\title{
Layered CeSO and LiCeSO Oxide Chalcogenides Obtained via Topotactic Oxidative and Reductive Transformations
}

Simon J. Cassidy, ${ }^{\dagger}$ Michael J. Pitcher, ${ }^{\dagger}$ Jared J. K. Lim, ${ }^{\dagger}$ Joke Hadermann, ${ }^{\ddagger}{ }^{\circ}$ Jeremy P. Allen, ${ }^{\S}$ Graeme W. Watson, ${ }^{\S}$ Sylvia Britto, $"$ Elena J. Chong, ${ }^{\dagger}$ David G. Free, ${ }^{\dagger}$ Clare P. Grey, and Simon J. Clarke*,†

${ }^{\dagger}$ Department of Chemistry, University of Oxford, Inorganic Chemistry Laboratory, South Parks Road, Oxford OX1 3QR, United Kingdom

${ }^{\ddagger}$ Electron Microscopy for Materials Science (EMAT), University of Antwerp, Groenenborgerlaan 171, B-2020 Antwerp, Belgium ${ }^{\S}$ School of Chemistry \& CRANN, Trinity College Dublin, Dublin 2, Ireland

"Department of Chemistry, University of Cambridge, Lensfield Road, Cambridge CB2 1EW, United Kingdom

\author{
Supporting Information
}

\begin{abstract}
The chemical accessibility of the $\mathrm{Ce}^{\mathrm{IV}}$ oxidation state enables redox chemistry to be performed on the naturally coinagemetal-deficient phases $\mathrm{CeM}_{1-x} \mathrm{SO}(\mathrm{M}=\mathrm{Cu}, \mathrm{Ag})$. A metastable black compound with the $\mathrm{PbFCl}$ structure type (space group P4/nmm: $a=$ 3.8396(1) $\AA, c=6.607(4) \AA, V=97.40(6) \AA^{3}$ ) and a composition approaching $\mathrm{CeSO}$ is obtained by deintercalation of $\mathrm{Ag}$ from $\mathrm{CeAg}{ }_{0.8} \mathrm{SO}$. High-resolution transmission electron microscopy reveals the presence of large defect-free regions in $\mathrm{CeSO}$, but stacking faults are also evident which can be incorporated into a quantitative model to account for the severe peak anisotropy evident in all the highresolution X-ray and neutron diffractograms of bulk CeSO samples; these suggest that a few percent of residual Ag remains. A strawcolored compound with the filled $\mathrm{PbFCl}$ (i.e., $\mathrm{ZrSiCuAs}$ - or $\mathrm{HfCuSi}_{2}$ -

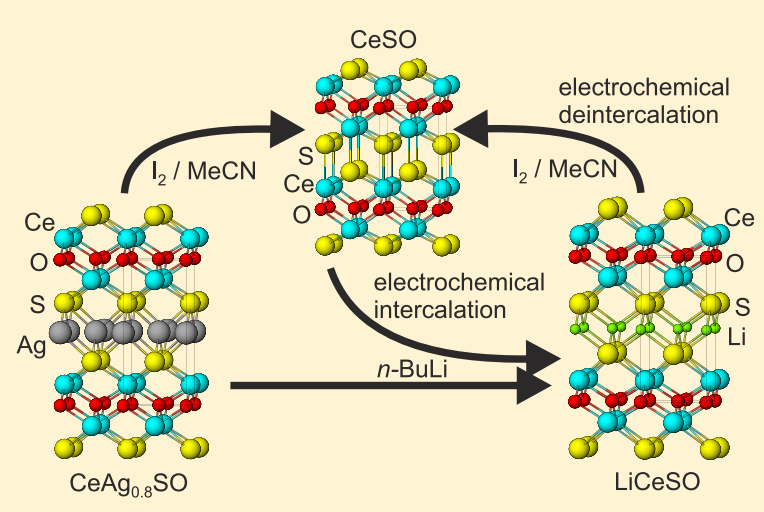
type) structure (space group P4/nmm: $\left.a=3.98171(1) \AA, c=8.70913(5) \AA, V=138.075(1) \AA^{3}\right)$ and a composition close to $\mathrm{LiCeSO}$, but with small amounts of residual $\mathrm{Ag}$, is obtained by direct reductive lithiation of $\mathrm{CeAg}_{0.8} \mathrm{SO}$ or by insertion of $\mathrm{Li}$ into $\mathrm{CeSO}$ using chemical or electrochemical means. Computation of the band structure of pure, stoichiometric CeSO predicts it to be a $\mathrm{Ce}^{4+}$ compound with the $4 \mathrm{f}$-states lying approximately $1 \mathrm{eV}$ above the sulfide-dominated valence band maximum. Accordingly, the effective magnetic moment per Ce ion measured in the CeSO samples is much reduced from the value found for the $\mathrm{Ce}^{3+}$-containing $\mathrm{LiCeSO}$, and the residual paramagnetism corresponds to the $\mathrm{Ce}^{3+}$ ions remaining due to the presence of residual $\mathrm{Ag}$, which presumably reflects the difficulty of stabilizing $\mathrm{Ce}^{4+}$ in the presence of sulfide $\left(\mathrm{S}^{2-}\right)$. Comparison of the behavior of $\mathrm{CeCu}_{0.8} \mathrm{SO}$ with that of $\mathrm{CeAg}_{0.8} \mathrm{SO}$ reveals much slower reaction kinetics associated with the Cu $\mathrm{C}_{1-x} \mathrm{~S}$ layers, and this enables intermediate $\mathrm{CeCu}_{1-x} \mathrm{Li}_{x} \mathrm{SO}$ phases to be isolated.
\end{abstract}

\section{INTRODUCTION}

$\mathrm{CeCuSO}^{1}$ and $\mathrm{CeAg}_{0.8} \mathrm{SO}^{2}$ crystallize in the tetragonal $\mathrm{ZrCuSiAs}$ structure (Figure 1), consisting of alternately stacked $\mathrm{PbO}$-type $\mathrm{CeO}$ layers and anti-PbO-type $\mathrm{CuS}$ layers. Oxide chalcogenides and oxide pnictides with these structures offer diverse properties with potential applications as transparent conductors (e.g., LaCuSO derivatives), ${ }^{3}$ high-temperature superconductors (e.g., LaFeAsO derivatives), ${ }^{4}$ and fast ion conductors enabled by the high mobility of coinage metal $(\mathrm{Cu}$ and $\mathrm{Ag})$ ions in chalcogenide layers (e.g., LaAgSO). ${ }^{5}$ The structures and properties of compounds in this class have been reviewed. ${ }^{6,7}$ If such oxide chalcogenide compounds contain oxidizable cations, then oxidative deintercalation of the coinage metal may be possible. We have previously shown that some samples reported as "CeCuSO" did not conform to the expectations of the lanthanide contraction because facile oxidation of $\mathrm{CeCuSO}$ occurs in moist air to form $\mathrm{CeCu}_{0.87} \mathrm{SO}$ and $\mathrm{CuO}$, with $\mathrm{Ce}$ oxidized above the +3 oxidation state, ${ }^{1}$ and similar behavior can be exploited in the property tuning of other oxide chalcogenides, notably $\mathrm{Sr}_{2} \mathrm{CoO}_{2} \mathrm{Cu}_{2} \mathrm{~S}_{2}$ which oxidizes readily in moist air, ${ }^{8}$ and $\mathrm{Sr}_{2} \mathrm{MnO}_{2} \mathrm{Cu}_{1.5} \mathrm{~S}_{2}$ which may be oxidized to $\mathrm{Sr}_{2} \mathrm{MnO}_{2} \mathrm{Cu}_{1.3} \mathrm{~S}_{2}$ using iodine solution, ${ }^{9}$ resulting in significant changes in the details of the crystal structures and the magnetic ordering. Here, we report that the $\mathrm{CeAg}_{1-x} \mathrm{SO}$ system is intrinsically Ag-deficient and exploit the high $\mathrm{Ag}$ mobility and the $\mathrm{Ce}^{3+/ 4+}$ redox chemistry to form the new metastable ternary compound with a composition approaching $\mathrm{CeSO}$ which lies close to the limiting composition at which $\mathrm{Ce}^{4+}$ can be stabilized in a sulfide-rich environment

Received: December 14, 2018

Published: February 25, 2019 


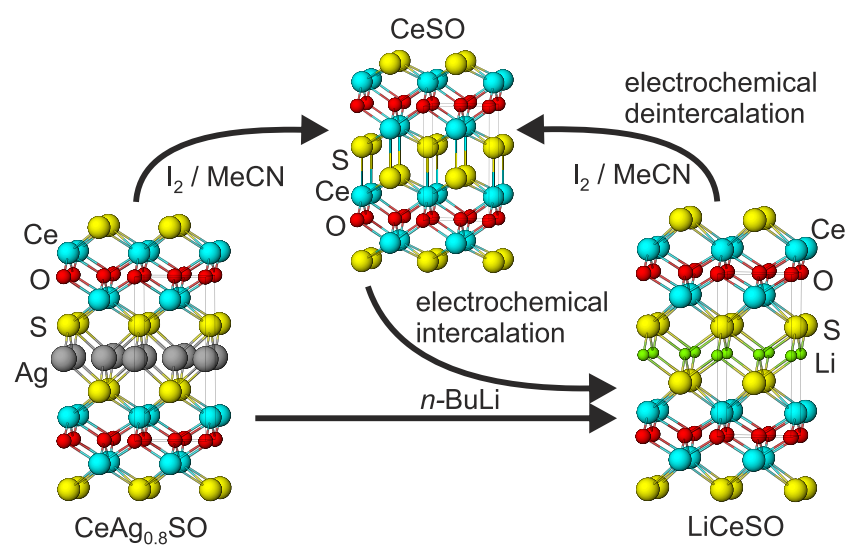

Figure 1. Summary of the ambient temperature transformations of $\mathrm{CeAg}_{0.8} \mathrm{SO}$ and its derivatives.

without oxidation of the sulfide anion. We further demonstrate the reversible lithiation of $\mathrm{CeAg}_{0.8} \mathrm{SO}$ and $\mathrm{CeSO}$ to form $\mathrm{LiCeSO}$.

\section{EXPERIMENTAL SECTION}

Synthesis. Due to the air sensitivity of some of the reactants and products, all manipulations were carried out in an argon-filled Glovebox Technology drybox or under nitrogen using Schlenk techniques. The precursor $\mathrm{CeAg}_{0.8} \mathrm{OS}$ was prepared as a single-phase, polycrystalline powder from a mixture of $\mathrm{CeS}_{2}$ synthesized from the elements (see Supporting Information (SI)), $\mathrm{CeO}_{2}$ (predried at 900 ${ }^{\circ} \mathrm{C}$; Alfa, 99.99\%), and Ag (Alfa, 99.99\%) in a 1:1:1.6 molar ratio. This mixture was ground, pelletized, and heated at $700{ }^{\circ} \mathrm{C}$ for 6 days in a dried, evacuated silica vessel with an alumina liner. Single-phase polycrystalline powders of the $\mathrm{Cu}$ analogue $\mathrm{CeCu}_{0.8} \mathrm{OS}$ were prepared on the scale of a few grams by heating a ground, pelletized mixture of $\mathrm{CeCuS}_{2}$, ${ }^{1,10} \mathrm{CeO}_{2}$ (Alfa, 99.99\%), and $\mathrm{Cu}$ (Alfa, 99.999\%) in the mole ratio $1: 1: 0.6$ at $1100{ }^{\circ} \mathrm{C}$ for 7 days. Reductive lithiation reactions on $\mathrm{CeAg}_{0.8} \mathrm{OS}$ and $\mathrm{CeCu}_{0.8}$ OS were performed by reacting the compounds with a 5 -fold molar excess of $n$-BuLi (1.6 M in hexane) under nitrogen at ambient temperature with overnight stirring. The products were filtered, washed twice with hexane, dried under vacuum, and unloaded/stored under argon in the glovebox. Oxidative deintercalation reactions on $\mathrm{CeAg}_{0.8} \mathrm{OS}$ were carried out in the following way: the powder was suspended in a dry acetonitrile

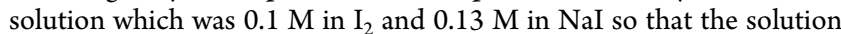
contained $\mathrm{CeAg}_{0.8} \mathrm{SO}, \mathrm{I}_{2}$, and $\mathrm{NaI}$ in the mole ratio 1:1.5:2. The solution was stirred overnight under nitrogen. The product was filtered, washed with dry acetonitrile, dried under vacuum, and stored under argon.

Electrochemical lithiation of a CeSO sample which had been synthesized from $\mathrm{CeAg}_{0.8} \mathrm{SO}$ by the reaction with iodine was performed with a positive electrode composed of CeSO mixed with Super $\mathrm{P}$ conductive carbon black in a weight ratio of 85:15. Coin-type half cells containing the positive electrode, $\mathrm{Li}$ metal as counter elecrode, borosilicate glass fiber separator (Whatman), and electrolyte ( $1 \mathrm{M} \mathrm{LiPF}_{6}$ in ethylene carbonate (EC)/dimethyl carbonate (DMC) $1: 1(\mathrm{v} / \mathrm{v} ;$ Merck)) were assembled in an argon-filled glovebox. Cycling was carried out at rates of $\mathrm{C} / 10$ or $\mathrm{C} / 30$ (the latter for in situ $\mathrm{X}$-ray diffraction; i.e., 10 or $30 \mathrm{~h}$ to reach the theoretical capacity corresponding to $1 \mathrm{~mol}$ of $\mathrm{Li}$ intercalated into $1 \mathrm{~mol}$ of $\mathrm{CeSO}$ ) using an Arbin battery cycler.

Structural Analysis. Detailed structural information for the $\mathrm{CeCu}_{0.8} \mathrm{OS}$ and $\mathrm{CeAg}_{0.8} \mathrm{OS}$ precursors and for the products obtained from soft chemical reductions or oxidations was obtained by synchrotron powder X-ray diffraction (PXRD) using beamline I1 1 (Diamond Light Source, Harwell, UK) ${ }^{11}$ with a Si-calibrated incident wavelength of approximately $0.823 \AA$ or beamline ID31 (ESRF, Grenoble, France $)^{12}$ with a Si-calibrated incident wavelength of aproximately $0.4 \AA$ (see figure captions for precise values for each diffractogram) and with samples sealed in $0.5 \mathrm{~mm}$ diameter capillaries. This was followed by time-of-flight powder neutron diffraction (PND), using either the high-resolution instrument HRPD or the medium-resolution, high-flux instrument POLARIS ${ }^{13}$ at the ISIS pulsed neutron facility on separate large samples of the products; samples were contained in $6 \mathrm{~mm}$ diameter vanadium cans sealed with indium gaskets. The samples synthesized electrochemically were examined ex situ and in situ using a PANalytical Empyrean powder diffractometer using $\mathrm{Cu} \mathrm{K} \alpha_{1} / \mathrm{K} \alpha_{2}$ radiation. Rietveld analysis was performed using the Topas Academic software ${ }^{14}$ with the capability of Version 6 of the software ${ }^{15}$ enabling the quantitative treatment of stacking faults in some of the samples.

Transmission Electron Microscopy Measurements. Selected area electron diffraction patterns were taken using a Philips CM20 transmission electron microscope (200 kV, equipped with CCD camera). High-angle annular dark field scanning transmission electron microscopy (HAADF-STEM) images were obtained using a FEI Titan 80-300 "cubed" microscope equipped with a Super-X detector and operated at $300 \mathrm{kV}$. Samples for transmission electron microscopy were prepared by crushing the powder in ethanol and depositing the solution on a copper grid covered with holey carbon.

Magnetometry. All measurements used a Quantum Design MPMS-XL SQUID magnetometer with samples of approximately 30 $\mathrm{mg}$ in mass contained in gelatin capsules. Measurements of the magnetic moment of the sample were made in fields of 3 and $4 \mathrm{~T}$ in the temperature range $5-300 \mathrm{~K}$, and the magnetic susceptibility was determined from the difference in the measurements in the two fields; this was to ensure the measurements were not compromised by lowfield nonlinearity in the sample moment with field as a consequence of minuscule amounts of ferromagnetic impurity.

Computation. All calculations were performed using the periodic density functional theory (DFT) code VASP, ${ }^{16,17}$ which employs a plane-wave basis set to describe the valence electronic states. The Perdew-Burke-Ernzerhof (PBE) ${ }^{18}$ gradient-corrected functional was used to treat the exchange and correlation. Interactions between the core (Ce:[Xe], O:[He], S:[Ne], Li:[He]) and the valence electrons were described using the projector-augmented wave ${ }^{19}$ (PAW) method. The screened hybrid-DFT methodology of Heyd, Scuseria, and Ernzerhof (HSE06) $)^{20-22}$ was used, replacing $25 \%$ of the PBE exchange with exact Fock exchange, as described in detail elsewhere. ${ }^{23}$ The HSE06 approach has previously been shown to give improved results for semiconducting systems over GGA and meta-GGA approaches, including accurate calculation of structures and band gaps, $^{24-27}$ and simulation of defective ${ }^{28-31}$ and magnetic ${ }^{32-34}$ systems.

In the calculations, structural optimizations of the bulk materials were performed at a series of volumes in order to calculate the equilibrium lattice parameters. In each case, the atomic positions, lattice vectors, and cell angles were allowed to relax, while the total volume was held constant. The resulting energy-volume curves were fitted to the Murnaghan equation of state ${ }^{35}$ to obtain the equilibrium bulk cell volume. This approach avoids the isotropic problems of Pulay stress and changes in basis set which can accompany volume changes in plane wave calculations. ${ }^{36}$ Convergence with respect to $k$ point sampling and plane-wave energy cutoff were checked, with a cutoff of $500 \mathrm{eV}$ and a $k$-point sampling of $5 \times 5 \times 3$ with a $\Gamma$ centered mesh found to be sufficient for both LiCeSO and CeSO. Structural optimizations were deemed to have converged when the force on every ion was less than $0.01 \mathrm{eV} \AA^{-1}$. Bader charges were calculated using Henkelman's code ${ }^{37}$ in which the distribution of the valence charge density is calculated using electron basins defined from the total charge density. This ensures that basins can be properly defined for atoms with very few valence electrons such as Li. The Bader charges given for $\mathrm{CeO}_{2}$ are taken from a unit cell minimized using an identical HSE06 methodology and a $6 \times 6 \times 6$ MonkhorstPack $k$-point mesh.

All optical absorption spectra, as well as the optical transition matrices, were calculated within the transversal approximation. ${ }^{38}$ This approach sums all direct valence band $(\mathrm{VB})$ to conduction band $(\mathrm{CB})$ transitions on the $k$-point grids to determine the optical absorption 
and does not include indirect and intraband transitions. ${ }^{39}$ As only single-particle transitions are included, any electron-hole correlations would require higher-order electronic structure methods. ${ }^{40,41}$ However, this approach has been shown to provide reasonable optical absorption spectra in comparison with experiment. ${ }^{42-45}$

\section{RESULTS}

Soft Chemical Transformations of $\mathrm{CeAg}_{0.8} \mathrm{SO}$. $\mathrm{CeAg}_{1-x} \mathrm{SO}$ has previously been characterized as being intrinsically Ag-deficient by Chan et al., ${ }^{2}$ from single crystal $\mathrm{X}$-ray diffraction studies of a sample with refined composition $\mathrm{CeAg}_{0.77} \mathrm{SO}$. The same authors used evidence from powder diffraction measurements to suggest that stoichiometric CeAgSO with significantly larger unit cell parameters than those of their well-characterized crystal was attainable. We attempted to synthesize stoichiometric CeAgSO, but all these attempts were unsuccessful with excess elemental Ag evident in the powder diffraction patterns of samples of composition CeAgSO. Comparison of the unit cell volumes of $\mathrm{LnAgSO}$ and $\mathrm{LnCuSO}$ (which are stoichiometric for less oxidizable lanthanides than $\mathrm{Ce}$ ) with our reported results for stoichiometric $\mathrm{CeCuSO}^{1}$ and the reported cell volume for the proposed stoichiometric "CeAgSO" is consistent with the results of our syntheses that the maximum $\mathrm{Ag}$ content obtainable using the high-temperature synthesis is close to $\mathrm{CeAg}_{0.9} \mathrm{SO}$. Further description and analysis on this point is supplied in the SI (Table S1, Figure S1). For the chemical transformations, we synthesized phase pure samples of composition $\mathrm{CeAg}_{0.8} \mathrm{SO}$ (i.e., close to the single crystal results already reported by Chan et al. ${ }^{2}$ ). See Figure S2 and Table S2.

Ambient temperature lithiation using $n-\mathrm{BuLi}$ of black $\mathrm{CeAg}_{0.8} \mathrm{SO}$ resulted in the formation of a dark-green product and a decrease in the unit cell volume by $2.1 \%$ but with apparent retention of the crystal structure. The laboratory PXRD data showed enormous changes in the intensities of the reflections compared with $\mathrm{CeAg}_{0.8} \mathrm{SO}$, and quantitative Rietveld analysis showed that nearly all the $\mathrm{Ag}$ had been extruded as the element and replaced with $\mathrm{Li}$ with the formation of a product of approximate composition $\mathrm{LiCeSO}$. This complete, or almost complete, extrusion of the coinage metal on lithiation is similar to that observed in the structurally related $\mathrm{Sr}_{2} \mathrm{MnO}_{2} \mathrm{Cu}_{2 m-0.5} \mathrm{~S}_{m+1}$ series, ${ }^{46-48}$ and in other chalcogenides such as the thiospinel $\mathrm{CuZr}_{2} \mathrm{~S}_{4}{ }^{49}$

Further reaction with iodine in acetonitrile of this product "LiCeSO + 0.8Ag" obtained from the lithiation of $\mathrm{CeAg}_{0.8} \mathrm{SO}$ or, alternatively, direct reaction of $\mathrm{CeAg}_{0.8} \mathrm{SO}$ with $\mathrm{I}_{2} / \mathrm{NaI}$ in acetonitrile resulted in the formation of a new product that could still be indexed on a primitive tetragonal unit cell, but with a unit cell volume that was $32 \%$ smaller than that of $\mathrm{CeAg}_{0.8} \mathrm{SO}$ and with the contraction dominated by a $27 \%$ shortening of the $c$ lattice parameter. The products of iodination reactions with either "LiCeSO $+0.8 \mathrm{Ag}$ " or $\mathrm{CeAg}_{0.8} \mathrm{SO}$ had similar lattice parameters suggesting that a common product had been produced. Addition of NaI to the solution of $\mathrm{I}_{2}$ in acetonitrile as described in the Experimental Section resulted in solubilization of the $\mathrm{AgI}^{50}$ enabling it to be washed away, thus yielding uncontaminated products. Quantitative analysis of the PXRD data was consistent with the topotactic formation of the product with a composition very close to stoichiometric $\mathrm{CeSO}$ with the $\mathrm{PbFCl}$ structure type, making the compound analogous to $\mathrm{ThSO}^{51}$ and the high-pressure tetragonal polymorph of $\mathrm{ZrSO},{ }^{52,53}$ by extraction of the $\mathrm{Ag}$ or $\mathrm{Li}$ from the sulfide layer. Subsequently, the synthesis of a sample approaching the CeSO composition by the direct iodination of $\mathrm{CeAg}_{0.8} \mathrm{SO}$ enabled lithiation using $n$ $\mathrm{BuLi}$ to be used to produce a sample of pale-yellow LiCeSO free from contamination by elemental $\mathrm{Ag}$, and such a sample of $\mathrm{CeSO}$ was also used in investigations of the electrochemical intercalation of $\mathrm{Li}$. We also verified that $\mathrm{CeSO}$ is metastable and requires these low-temperature synthetic methods. Heating to $700{ }^{\circ} \mathrm{C}$ resulted in the formation of mixed-valent $\mathrm{Ce}_{4} \mathrm{O}_{4} \mathrm{~S}_{3}$, which is known to decompose further to the fully reduced $\mathrm{Ce}_{2} \mathrm{O}_{2} \mathrm{~S}$ at higher temperatures. ${ }^{54}$ Figure 1 summarizes the chemical transformations applied to $\mathrm{CeAg}_{0.8} \mathrm{SO}$ and its derivatives. Analyses of the compositions, crystal structures, magnetic properties, and electrochemistry of these experimental samples approaching the compositions $\mathrm{LiCeSO}$ and $\mathrm{CeSO}$, together with discussion of the electronic structures of stoichiometric $\mathrm{LiCeSO}$ and $\mathrm{CeSO}$, are presented below.

Structural Characterization of LiCeSO. Figure 2 shows the results of Rietveld refinement against synchrotron PXRD

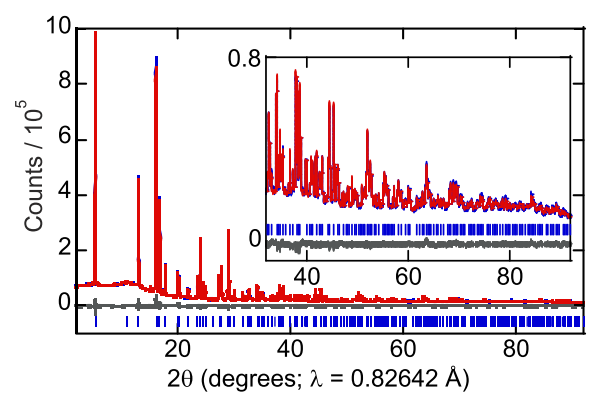

Figure 2. Rietveld refinement against PXRD data (I11, diamond $(\lambda=$ $0.82642 \AA)$ ) for a sample of LiCeSO prepared by lithiation of CeSO. Data (blue), fit (red), and difference (gray) curves are plotted. Tick marks indicate the reflections of the LiCeSO phase.

data obtained on a sample of LiCeSO free of elemental $\mathrm{Ag}$ produced by lithiation of a sample of $\mathrm{CeSO}$ obtained by direct $\mathrm{Ag}$ deintercalation from $\mathrm{CeAg}_{0.8} \mathrm{SO}$. Figure 3 shows a

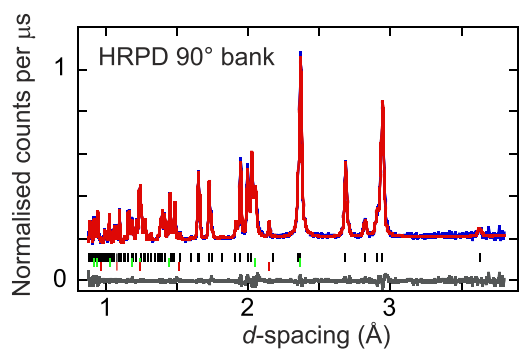

Figure 3. Rietveld refinement against HRPD PND data of a sample prepared by lithiation of $\mathrm{CeAg}_{0.8} \mathrm{SO}$. Data (blue), fit (red), and difference (gray) curves are plotted. Tick marks indicate the reflections of the observed phases (black (upper), LiCeSO; green (middle), Ag; red (lower), V sample container). Data from the data bank located at $2 \theta=90^{\circ}$ are shown; data from the $168^{\circ}$ bank are included as Supporting Information (Figure S3).

refinement against PND data on an elemental-Ag-containing sample obtained by direct lithiation of $\mathrm{CeAg}_{0.8} \mathrm{SO}$. The crystal structure was refined in space group $P 4 / \mathrm{nmm}$ using the structure of $\mathrm{CeAg}_{0.8} \mathrm{SO}$ as the starting model. The key refinement parameters are listed in Table 1, and further structural details are supplied in Table 3. 
Table 1. Refinement Parameters for Two LiCeSO Samples

\begin{tabular}{lll} 
& \multicolumn{1}{c}{$\mathrm{LiCeSO}^{a}$} & \multicolumn{1}{c}{$\mathrm{LiCeSO}^{b}$} \\
radiation & $\mathrm{X}$-rays, $\lambda=0.82642 \AA$ & neutron, time-of-flight \\
instrument & I11, diamond & HRPD, ISIS \\
temp $(\mathrm{K})$ & $298(2)$ & $298(2)$ \\
space group & $P 4 /$ nmm $^{c}$ & $P 4 /$ nmm $^{c}$ \\
$a(\AA)$ & $3.98171(1)$ & $3.9825(2)$ \\
$c(\AA)$ & $8.70913(5)$ & $8.7038(5)$ \\
$V\left(\AA^{3}\right)$ & $138.075(1)$ & $138.05(2)$ \\
$z(\mathrm{Ce})^{c}$ & $0.14115(2)$ & $0.1418(1)$ \\
$z(\mathrm{~S})^{c}$ & $0.66843(8)$ & $0.6645(3)$ \\
$\mathrm{Occ}(\mathrm{Li}) / \mathrm{Occ}(\mathrm{Ag})$ & $0.9455(5) / 0.0545(5)$ & $0.985(3) / 0.015(3)$ \\
$U_{11}(\mathrm{Li}) / U_{\text {iso }}(\mathrm{Li})\left(\AA^{2}\right)$ & $0.0127(7)^{d}$ & $0.015(1)$ \\
$U_{33}(\mathrm{Li})\left(\AA^{2}\right)$ & & $0.006(2)$ \\
$U_{11}(\mathrm{Ce})\left(\AA^{2}\right)$ & $0.00664(6)$ & $0.0089(6)$ \\
$U_{33}(\mathrm{Ce})\left(\AA^{2}\right)$ & $0.0052(1)$ & $0.0134(9)$ \\
$U_{11}(\mathrm{~S}) / U_{\text {iso }}(\mathrm{S})\left(\AA^{2}\right)$ & $0.0094(2)^{d}$ & $0.0093(7)$ \\
$U_{33}(\mathrm{~S})\left(\AA^{2}\right)$ & & $0.022(2)$ \\
$U_{11}(\mathrm{O}) / U_{\text {iso }}(\mathrm{O})\left(\AA^{2}\right)$ & $0.0041(5)^{d}$ & $0.0051(5)$ \\
$U_{33}(\mathrm{O})\left(\AA^{2}\right)$ & & $0.0175(9)$ \\
$R_{\text {wp }}(\%)$ & 2.23 & 2.73 \\
$\chi^{2}$ & 4.15 & 1.33
\end{tabular}

${ }^{a}$ Prepared from CeSO. ${ }^{b}$ Prepared by direct lithiation of $\mathrm{CeAg}_{0.8} \mathrm{SO}$ (sample contains elemental Ag). ${ }^{c}$ Origin choice 1 (inversion center at $(1 / 4,1 / 4,0)): \mathrm{Li} / \mathrm{Ag}, 2 b(0,0,1 / 2) ; \mathrm{Ce}, 2 c(1 / 2,0, z) ; \mathrm{S}, 2 c(1 / 2,0$, $z)$; O, $2 a(0,0,0) .{ }^{d}$ Refined isotropically.

The contraction in unit cell volume on transforming $\mathrm{CeAg}_{0.8} \mathrm{SO}$ to $\mathrm{LiCeSO}$ is dominated by a contraction along the stacking direction ( $c$ parameter), consistent with the decrease of ionic radius of the ion in the tetrahedral sites in the sulfide layer (tetrahedral $\mathrm{Ag}^{+}=114 \mathrm{pm} \mathrm{vs} \mathrm{Li}^{+}=73 \mathrm{pm}$ ). ${ }^{55}$ Analysis of the diffraction data on different samples suggested that there was a small amount of residual $\mathrm{Ag}$ that was not extruded in the reactions. A sample obtained by intercalation of $\mathrm{Li}$ into $\mathrm{CeSO}$ had a refined composition of $\mathrm{Li}_{0.9455(5)}$ $\mathrm{Ag}_{0.0545(5)} \mathrm{CeSO}$ (Table 1 and Figure 2), and this has implications for the precise composition of $\mathrm{CeSO}$ as discussed below. Analysis of PND data on a sample obtained from direct lithiation of $\mathrm{CeAg}_{0.8} \mathrm{SO}$ (Table 1 and Figure 3) yielded a refined composition of $\mathrm{Li}_{0.987(3)} \mathrm{Ag}_{0.013(3)} \mathrm{CeSO}$ (with the refinement constrained such that the site must be fully occupied). This analysis is complicated slightly by the negative neutron scattering length of $\mathrm{Li}$, and an alternative model with no $\mathrm{Ag}$ on the $2 b$ site and free refinement of the Li occupancy yielded a refined composition with a significant Li-deficiency of $\mathrm{Li}_{0.95(1)} \mathrm{CeSO}$. The two models are not distinguishable by PND alone, but consideration of both the XRD refinements which suggest that the scattering in the sulfide layer corresponds to slightly more than one $\mathrm{Li}$ ion, and the fact that the lithiations were carried out with excess $n-\mathrm{BuLi}$, suggests that the compound we describe as LiCeSO contains a sulfide layer fully occupied by Li ions apart from a small number $(\sim 1-5 \%)$ of residual $\mathrm{Ag}$ ions. Hence, the experimentally prepared samples reproducibly do not quite reach the LiCeSO stoichiometry. Similar behavior is found in the lithiation of the thiospinel $\mathrm{CuZr}_{2} \mathrm{~S}_{4}{ }^{49}$

Structural Characterization of CeSO. Rietveld refinement against PXRD (Figure S4) and PND data (Figure 4) was consistent with the topotactic formation of the product $\mathrm{CeSO}$ with the $\mathrm{PbFCl}$ structure type by complete oxidative deintercalation of either $\mathrm{Ag}$ or $\mathrm{Li}$ from the sulfide layers of

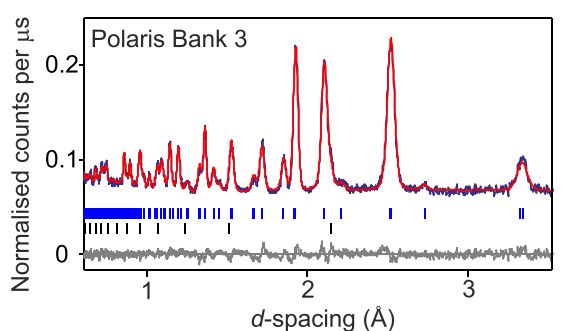

Figure 4. Rietveld refinement against POLARIS PND data of a sample of $\mathrm{CeSO}$ prepared by direct oxidative deintercalation of $\mathrm{Ag}$ from $\mathrm{CeAg}_{0.8} \mathrm{SO}$. Data (blue), fit (red), and difference (gray) curves are plotted. Tick marks indicate the reflections of the observed phases (blue (upper), CeSO; black (lower), V sample container). Data from the detectors located at $2 \theta=49.5^{\circ}$ are shown.

$\mathrm{CeAg}_{0.8} \mathrm{SO}$ or $\mathrm{LiCeSO}$, respectively, making the compound analogous to oxide chalcogenides of metals that can readily attain the +4 oxidation state: $\mathrm{ZrSO},{ }^{52,53} \mathrm{ThSO}$, USO, and NpSO. ${ }^{51}$ Full analysis of the crystal structure (using powder diffraction and TEM, Figures 4-7), properties, and electrochemistry was carried out on a single sample of $\mathrm{CeSO}$ prepared by direct oxidative deintercalation of $\mathrm{Ag}$ from $\mathrm{CeAg}_{0.8} \mathrm{SO}$.

The refinements showed that the deintercalation of $\mathrm{Ag}$ is topotactic and simply involves the removal of the tetrahedral coinage metal cation with collapse of the structure along the $c$ axis, so that compared with $\mathrm{CeAg}_{0.8} \mathrm{SO}$ the $c$ lattice parameter decreases by $27 \%$ and the Ce coordination number increases from $4 \times \mathrm{S}+4 \times \mathrm{O}$ to $5 \times \mathrm{S}+4 \times \mathrm{O}$ as shown in Figure 1 and

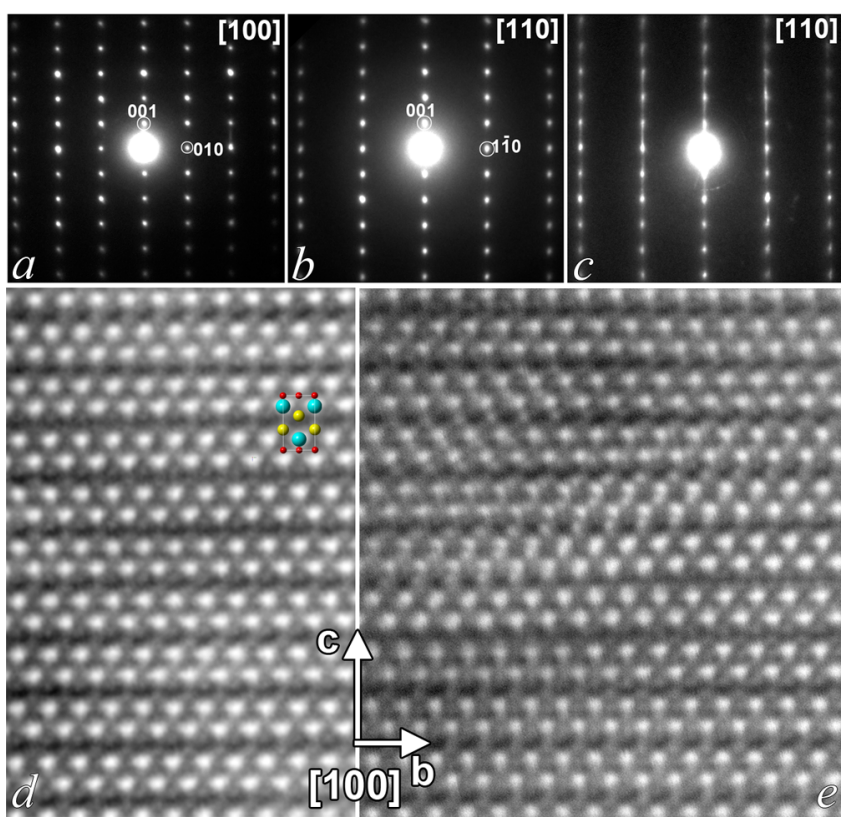

Figure 5. $(a-c)$ Electron diffraction patterns viewed along the [100] and [110] zone axes for the sample of CeSO used for the synchrotron PXRD, PND, and electrochemical measurements. The patterns show evidence for inhomogeneity with some parts of the sample exhibiting streaks along the $c^{*}$ reciprocal lattice direction (seen in the [110] zone shown in part $c$, but not in part $b$ ) which are indicative of stacking disorder. (d, e) HAADF-STEM images showing wellcrystallized portions of CeSO (d) as well as regions where stacking faults are clearly evident (e). The structural model has been superimposed in part $d$ to show correspondence of the different columns to the different atoms, with the brightest columns being $\mathrm{Ce}$, and less bright columns being $S$. 


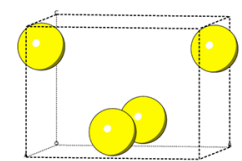

$\mathrm{S}_{2}$

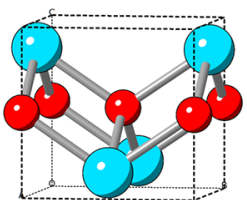

$\mathrm{Ce}_{2} \mathrm{O}_{2}$

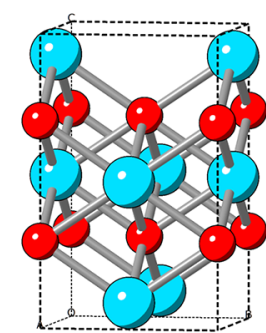

$\mathrm{Ce}_{4} \mathrm{O}_{4}$

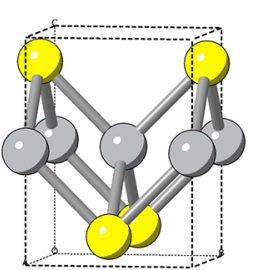

$\mathrm{Ag}_{2} \mathrm{~S}_{2}$

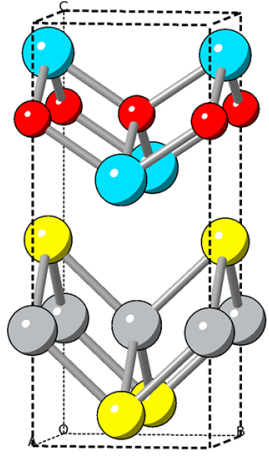

$\mathrm{Ce}_{2} \mathrm{O}_{2} \mathrm{Ag}_{2} \mathrm{~S}_{2}$

Figure 6. Various layers used to produce the faulted models (described in more detail in the text) for the structural analysis of CeSO. Idealized $\mathrm{CeSO}$ is composed of alternating $\mathrm{S}_{2}$ and $\mathrm{Ce}_{2} \mathrm{O}_{2}$ layers. Models A and C incorporated some $\mathrm{Ag}_{2} \mathrm{~S}_{2}$ layers instead of $\mathrm{S}_{2}$ layers. Model B incorporated some $\mathrm{Ce}_{4} \mathrm{O}_{4}$ layers instead of $\mathrm{Ce}_{2} \mathrm{O}_{2}$ layers. Key: $\mathrm{S}$, yellow; Ce, cyan; $\mathrm{O}$, red; $\mathrm{Ag}$, gray.

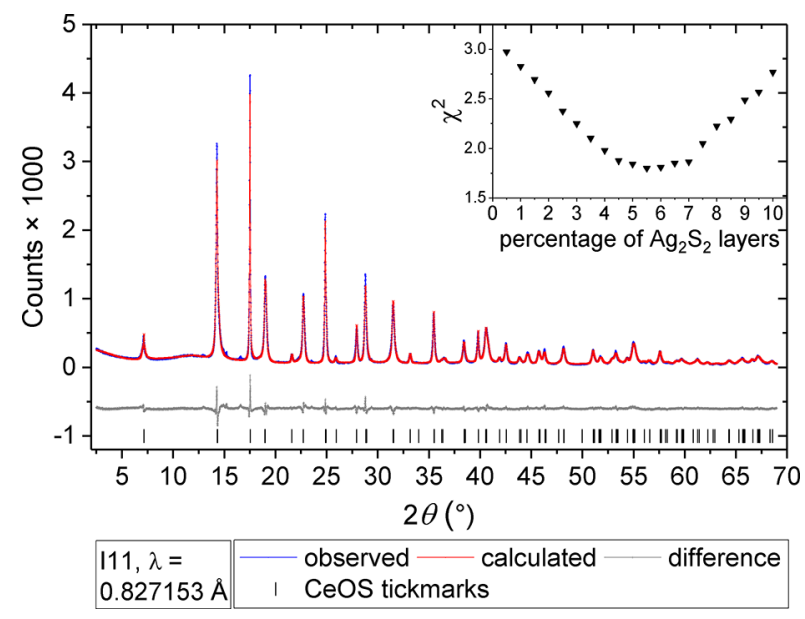

Figure 7. Rietveld refinement against synchrotron PXRD data $(\mathrm{I} 11 ; \lambda$ $=0.827153 \AA$ ) using a stacking fault model of CeSO with $5.5 \%$ silvercontaining sulfide layers $(79.5(5) \%)$ and a "faultless" phase of CeSO $(20.5(5) \%)$, as described in the main text. Tick marks show the reflection positions of $\mathrm{CeSO}$, which are contributed to by both the faulted and "faultless" models. Comparison of this treatment with alternative models is shown in Figures S4-S10.

described further below. The $P 4 / \mathrm{nmm}$ symmetry is retained. The structural parameters are compared below with those of $\mathrm{LiCeSO}$ and $\mathrm{CeAg}_{0.8} \mathrm{SO}$ in Table 3. Despite the removal of almost all the $\mathrm{Ag}^{+}$from the tetrahedral sites in the sulfide layers, there is no evidence for the formation of $S-S$ bonds following this oxidative deintercalation. This contrasts with the case for compounds with trivalent lanthanides in which compounds of formula $\mathrm{LnSO}$ contain $\left[\mathrm{S}_{2}\right]^{2-}$ ions. $^{56}$ The preliminary analyses of diffraction patterns of CeSO samples measured using high-resolution synchrotron X-ray diffraction using peak shapes with only Gaussian and Lorentzian terms to account for particle size and strain broadening (as used in the refinement of the LiCeSO model) were inadequate (Figure S4). Such a refinement gave a numerical goodness of fit parameter $\chi^{2}$ of 3.03 but generally accounted poorly for the shapes of the peaks: the $h k 0$ reflections were relatively narrow compared with the widths of $h k l$ reflections. For the refinement against POLARIS neutron data of medium resolution shown in Figure 4, this was modeled using a Stephens-type anisotropic peak broadening. ${ }^{57}$ In the analysis of the higher-resolution $\mathrm{X}$ ray data from I11, the fit to the integrated intensities using this commonly used treatment (Figure S5) gave an improved $\chi^{2}$ of 2.32 , but there remained a considerable mismatch to the profile, particularly to the best-resolved peaks at low angles with strong asymmetry: the $00 l$ reflections were overbroadened, and some reflections were found to be slightly out of position. Using the Stephens-type anisotropic peak broadening terms appropriate to an orthorhombic crystal structure gave some further improvement to the fit through the introduction of further parameters, but there was no evidence that the structure was lower in symmetry than tetragonal. We concluded that the Stephens-type anisotropic peak broadening is inadequate in accounting for high-resolution data on $\mathrm{CeSO}$, and the interpretation of this is discussed below.

Transmission electron microscopy measurements were performed on the same CeSO sample as was used in the PXRD and PND measurements in order to probe the crystal structure on a shorter length scale in an effort to account for the anomalies in the high-resolution synchrotron powder data. Electron diffraction patterns (Figure 5a,b) confirmed the cell deduced from PXRD and PND data, but the majority of [110] zones showed streaking along the $c^{*}$ direction, suggestive of stacking disorder (Figure 5c). In addition to the streaks, some additional, very weak reflections were also evident (see Figure S11), suggestive of a possible structural modulation on the length scale probed by electron diffraction. HAADF-STEM images revealed large well-ordered regions of the structure (Figure 5d and larger overview in Figure S12) but also revealed the presence of stacking faults (Figure 5e) which are consistent with the observation of the streaking evident in the electron diffractograms (Figure 5c) and with the broadening of the $l$ containing reflections in the PXRD patterns. On HAADFSTEM images, the brightness of the projected atom columns is approximately proportional to $Z^{2}$, where $Z$ is the atomic number; therefore, in Figure $5 \mathrm{~d}$ the brightest columns correspond to the Ce columns and the weaker ones to the $S$ columns. The sample was found to be somewhat unstable in the electron beam, so energy dispersive X-ray analysis with high spatial resolution was not able to test the possible scenarios such as the faulted regions containing some residual $\mathrm{Ag}$ atoms which had not been removed in the synthesis (as suggested by the analysis of the average structure of LiCeSO described above) or a more significant reconstruction of the structure, such as the formation of a fluorite-type region, or the formation of some disulfide units $\left(\left[\mathrm{S}_{2}\right]^{2-}\right)$ by sulfide oxidation rather than pure oxidation of $\mathrm{Ce}^{3+}$ to $\mathrm{Ce}^{4+}$. Moreover, the 
image in Figure 5e shows a complex set of features differing over the faulted region, most probably because of the projected character of HAADF-STEM images, which prevents deducing the precise nature of the stacking faults from the images.

In order to account for the asymmetry, anisotropic peak broadening, and positional mismatches evident in the standard Rietveld refinement against the synchrotron PXRD data, and to account for the evidence of stacking faults in regions of the sample obtained from the TEM measurements, we used the Topas Academic Version 6 software to perform Rietveld refinements that included stacking faults. ${ }^{15}$ Supercells were constructed using the stacking units shown in Figure 6 of either $\mathrm{Ce}_{2} \mathrm{O}_{2}, \mathrm{~S}_{2}, \mathrm{Ag}_{2} \mathrm{~S}_{2}, \mathrm{Ce}_{4} \mathrm{O}_{4}$, or $\mathrm{Ce}_{2} \mathrm{O}_{2} \mathrm{Ag}_{2} \mathrm{~S}_{2}$ in a method similar to that adopted by Ainsworth et al. ${ }^{58}$ Supercells of 3000 layers were constructed by assigning a probability for each type of layer stacking on top of each other type of layer. For example, a model equivalent to the unit cell of perfect, stoichiometric $\mathrm{CeSO}$ is described by assigning the probability of a $\mathrm{Ce}_{2} \mathrm{O}_{2}$ layer following a $\mathrm{S}_{2}$ layer to be 1 , assigning the probability of $\mathrm{a} \mathrm{S}_{2}$ layer following a $\mathrm{Ce}_{2} \mathrm{O}_{2}$ layer also to be 1 , and assigning all other possibilities to 0 . Using this methodology we considered the following: (model A) $0.5-10 \%$ of the sulfide layers containing silver, randomly distributed in the supercell; (model B) $0.5-10 \%$ of the cerium oxide layers being fluorite-type $\mathrm{Ce}_{4} \mathrm{O}_{4}$ layers, randomly distributed in the supercell; and (model C) $1-10 \%$ of sulfide layers containing silver, with a 5-70\% probability of the next sulfide layer also containing silver. Also considered was model D, a stack of 200 $\mathrm{Ce}_{2} \mathrm{O}_{2}$ and $\mathrm{S}_{2}$ layers only, with turbostratic disorder introduced by refining a shift of each layer in the $x y$ plane with respect to its neighbors, as is sometimes responsible for asymmetrically broadened line profiles in diffraction peaks of layered materials (e.g., in layered double hydroxides ${ }^{59}$ or kaolinite). ${ }^{60}$ Full details of how the models were implemented are given in the Supporting Information. Minimum $\chi^{2}$ values achieved for models A, B, C, and D were 1.80, 2.26, 1.82, and 2.53, respectively. The best fit of model $\mathrm{C}$ was one almost equivalent to model A, with poorer agreement achieved when a high probability of silver-containing layers clustering together was assigned. A plot of the agreement factor for the refinement, $\chi^{2}$, against concentration of $\mathrm{Ag}_{2} \mathrm{~S}_{2}$ layers gives the minimum value with $5.5 \%$ of such layers included (Figure 7 , inset). Since HAADF-STEM images (Figure 5d, Figure S12) show that some large regions of the sample contain no stacking faults, a "faultless" stoichiometric CeSO phase was added to the refinement, with its lattice parameters, atomic coordinates, and thermal displacements made equivalent to a summation of one $\mathrm{Ce}_{2} \mathrm{O}_{2}$ and one $\mathrm{S}_{2}$ layer. Inclusion of the faultless phase improved further to $\chi^{2}$ to 1.31 and accounted for $20 \%$ of the total scattering intensity which is consistent with the observation above that "the majority of [110] zones showed streaking [in the electron diffraction patterns].” The total percentage of sulfide layers containing silver is therefore estimated at $4.4 \%(0.8 \times 5.5 \%)$ by this refinement, shown in Figure 7, with refined structural parameters listed in Tables 2 and 3. Thus, the stacking fault model that best accounted for the profile contained a small proportion of sulfide layers from which Ag had not been removed. This is quantitatively consistent with the analysis of LiCeSO samples (which have much more well-behaved peak shapes) in which the average electron count of the species in the tetrahedral sites in the sulfide layers cannot be accounted for by full $\mathrm{Li}$ occupancy alone. It is proposed that these regions lead to some of the
Table 2. Description of the Models Used in the Refinements of $\mathrm{CeSO}$

\begin{tabular}{|c|c|c|c|c|c|c|}
\hline \multicolumn{7}{|c|}{ CeSO "Faultless" Model ${ }^{a}$} \\
\hline atom & site & \multicolumn{2}{|c|}{$x$} & $y$ & $z$ & $U_{\text {iso }}\left(\AA^{2}\right)$ \\
\hline Cel & $2 c$ & \multicolumn{2}{|c|}{0.5} & 0 & $0.1954(3)$ & $0.0085(1)$ \\
\hline S1 & $2 c$ & \multicolumn{2}{|c|}{0.5} & 0 & $0.6334(4)$ & $0.0078(5)$ \\
\hline $\mathrm{O} 1$ & $2 a$ & \multicolumn{2}{|c|}{0} & 0 & 0 & $0.016(2)$ \\
\hline \multicolumn{7}{|c|}{ Stacking Fault Model ${ }^{b}$} \\
\hline \multicolumn{2}{|l|}{ layer } & atom & $x$ & $y$ & $z$ in layer & $U_{\text {iso }}\left(\AA^{2}\right)$ \\
\hline \multirow{4}{*}{$\begin{array}{l}\mathrm{Ce}_{2} \mathrm{O}_{2} \\
c=3.788(2)\end{array}$} & & $\mathrm{Ce} 1$ & 0.5 & 0 & $z \mathrm{Ce} 1=0.8445(3)$ & $0.0085(1)$ \\
\hline & & $\mathrm{Ce} 2$ & 0 & 0.5 & $(1-z \mathrm{Ce} 1)$ & $0.0085(1)$ \\
\hline & & $\mathrm{O} 1$ & 0 & 0 & 0.5 & $0.016(2)$ \\
\hline & & $\mathrm{O} 2$ & 0.5 & 0.5 & 0.5 & $0.016(2)$ \\
\hline \multirow{2}{*}{\multicolumn{2}{|c|}{$\begin{array}{l}\mathrm{S}_{2} \\
c=2.822(2) \AA\end{array}$}} & S1 & 0.5 & 0 & $z \mathrm{~S} 1=0.828(1)$ & $0.0078(5)$ \\
\hline & & S2 & 0 & 0.5 & $(1-z S 1)$ & $0.0078(5)$ \\
\hline \multirow{4}{*}{$\begin{array}{l}\mathrm{Ag}_{2} \mathrm{~S}_{2} \\
c=5.195^{c} \AA\end{array}$} & & Ag1 & 0 & 0 & 0.5 & $0.051(4)$ \\
\hline & & $\mathrm{Ag} 2$ & 0.5 & 0.5 & 0.5 & $0.051(4)$ \\
\hline & & S3 & 0.5 & 0 & 0.87 & $0.0078(5)$ \\
\hline & & S4 & 0 & 0.5 & 0.13 & $0.0078(5)$ \\
\hline
\end{tabular}

${ }^{a_{T}}$ The faultless CeSO model in $\mathrm{P} 4 / \mathrm{nmm}$ (origin choice 1), $a=$ $3.8396(1) \AA$, $c=6.607(4) \AA$, constitutes $20.5(5) \%$ of the sample. ${ }^{b}$ The faulted model constituting $79.5(5) \%$ of the sample is constructed from three layers defined as layers with $P 1$ symmetry and $a=3.84251(6) \AA$ A Strict alternation of $\mathrm{Ce}_{2} \mathrm{O}_{2}$ layers and $\mathrm{S}_{2}$ layers only corresponds to the "faultless" phase. The occurrence of stacking faults where $\mathrm{Ag}_{2} \mathrm{~S}_{2}$ layers are incorporated is described in the text. ${ }^{c}$ Fixed value due to low fraction of these layers.

weak reflections evident in the electron diffractograms (Figure S11) as well as the streaks evident along the $c^{*}$ direction (Figure 5c). This behavior in which lithiation or direct deintercalation fails to fully extrude or deintercalate a few remaining percent of the coinage metal has precedent in the behavior of the thiospinel system $\mathrm{CuZr}_{2} \mathrm{~S}_{4}$ in which $\mathrm{Cu}$ extrusion by $\mathrm{Li}$ from $n$-BuLi to form $\mathrm{LiCuZr}_{2} \mathrm{~S}_{4}$ followed by oxidative deintercalation by $\mathrm{I}_{2}$ in $\mathrm{MeCN}$ produces $\mathrm{Cu}_{0.05} \mathrm{Zr}_{2} \mathrm{~S}_{4}{ }^{53}$

Magnetometry. The magnetic susceptibility of $\mathrm{Ce}^{3+}$ containing binary oxides has been described by Engelhardt and Figgis. ${ }^{61}$ They describe that crystal field effects generally reduce the effective moment from the free-ion value of $2.54 \mu_{\mathrm{B}}$, and that these effects result in very significant deviations from the Curie-Weiss law. In the case of LiCeSO, measurement of the magnetic susceptibility at $300 \mathrm{~K}$ yielded an effective magnetic moment of $2.28(1) \mu_{\mathrm{B}}$ which is very similar to the value found for $\mathrm{Ce}_{2} \mathrm{O}_{3}$ and $\mathrm{Ce}^{3+}$ ions in a $\mathrm{La}_{2} \mathrm{O}_{3}$ matrix by Engelhardt and Figgis. ${ }^{61}$ There was no evidence for magnetic ordering of the $\mathrm{Ce}^{3+}$ moments down to $5 \mathrm{~K}$. $\mathrm{CeAg}_{0.8} \mathrm{SO}$ had a susceptibility which could be accounted for by $79(1) \%$ of the Ce ions being $\mathrm{Ce}^{3+}$ with an effective moment of $2.28 \mu_{\mathrm{B}}$, consistent with the assumption that the Ag-deficiency results in $\mathrm{Ce}$ oxidation. The oxidized product $\mathrm{CeSO}$ had a much lower magnetic susceptibility than that of $\mathrm{LiCeSO}$ or $\mathrm{CeAg}_{0.8} \mathrm{SO}$ (Figure 8). Measurement at $300 \mathrm{~K}$ produced a value of the susceptibility that could be accounted for by $8(1) \%$ of the Ce ions with an effective moment of $2.28 \mu_{\mathrm{B}}$. These measurements show that the oxidation proceeds via the oxidation of $\mathrm{Ce}^{3+}$ and not $\mathrm{S}^{2-}$ which is consistent with the computational results shown below, and consistent with the relatively facile oxidation of $\mathrm{Ce}^{3+}$. The magnetometry is also in reasonable quantitative agreement with the interpretation of the stacking faults in the high-resolution powder X-ray diffraction data as arising from 
Table 3. Experimentally Observed (for $\mathrm{CeAg}_{0.8} \mathrm{SO}$, $\mathrm{LiCeSO}$, and CeSO) and HSE06-Calculated (for LiCeSO and CeSO) Lattice Parameters, Cell Volumes, and Bond Distances

\begin{tabular}{|c|c|c|c|c|c|}
\hline & \multirow[b]{2}{*}{$\mathrm{CeAg}_{0.8} \mathrm{SO} \operatorname{expt}^{b}$} & \multicolumn{2}{|c|}{ LiCeSO } & \multicolumn{2}{|c|}{$\mathrm{CeSO}$} \\
\hline & & HSE06 & $\operatorname{expt}^{c}$ & HSE06 & $\operatorname{expt}^{c}$ \\
\hline$T / \mathrm{K}$ & 298 & 0 & 298 & 0 & 298 \\
\hline$E_{\mathrm{AFM}}-E_{\mathrm{FM}}(\mathrm{meV})$ & & 0.30 & & & \\
\hline$a(\AA)$ & $3.9499(1)$ & $3.963(-0.5)^{a}$ & $3.9825(2)$ & $3.836(-0.3)^{a}$ & $3.8478(1)$ \\
\hline$c(\AA)$ & $9.0728(2)$ & $8.708(0.0)^{a}$ & $8.7038(5)$ & $6.605(-0.2)^{a}$ & $6.6191(6)$ \\
\hline$V\left(\AA^{3}\right)$ & $141.539(9)$ & $136.76(-1)^{a}$ & $138.05(2)$ & $97.16(-0.9)^{a}$ & $98.00(1)$ \\
\hline $\mathrm{Ce}-\mathrm{O}(\AA)$ & $2.3435(2)$ & $2.335(-0.3)^{a}$ & $2.3429(6)$ & $2.313(-0.6)^{a}$ & $2.326(1)$ \\
\hline $\mathrm{Ce}-\mathrm{S}(\AA ̊)(\times 4)$ & $3.1603(6)$ & $3.274(-0.2)^{a}$ & $3.282(1)$ & $2.936(-0.5)^{a}$ & $2.952(1)$ \\
\hline $\mathrm{Ce}-\mathrm{S}(\AA)(\times 1)$ & & & & $2.892(+1.2)^{a}$ & $2.858(3)$ \\
\hline $\mathrm{Li}-\mathrm{S}$ or $\mathrm{Ag}-\mathrm{S}(\AA)$ & $2.6677(9)$ & $2.441(-0.5)^{a}$ & $2.453(1)$ & & \\
\hline
\end{tabular}

${ }^{a}$ Percentage differences of calculated values from experimental values are given in parentheses. ${ }^{b}$ Values from refinements against ID31 data (Figure S2 and Table S2). ${ }^{c}$ Values from refinements against PND data (Figures 3 and 4 ).

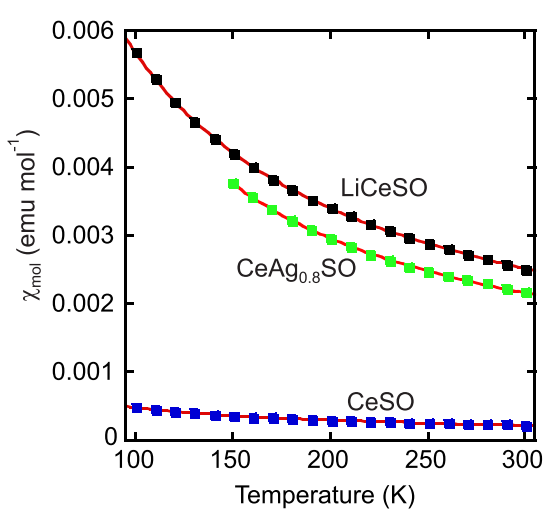

Figure 8. Magnetic susceptibilities of $\mathrm{LiCeSO}$ and $\mathrm{CeSO}$ in the range 100-300 K, with data for $\mathrm{CeAg}_{0.8} \mathrm{SO}$ shown for comparison. The lines are fits to a modified Curie-Weiss behavior $\chi_{\mathrm{mol}}=\chi_{0}+C /(T-$ $\theta)$, but see ref 61 for a discussion indicating that this is fortuitous for $\mathrm{Ce}^{3+}$. See also Figure S13.

the presence of remanent $\mathrm{Ag}^{+}$ions, each of which will yield one $\mathrm{Ce}^{3+}$ ion through considerations of charge balance. We cannot rule out that $\mathrm{Ce}^{3+}$ moments are also present in surface states.

Comparison of the Crystal Structures of LiCeSO and CeSO. The HSE06-calculated lattice parameters and bond lengths for idealized stoichiometric $\mathrm{LiCeSO}$ and $\mathrm{CeSO}$ are given in Table 3 where they are compared with the parameters obtained experimentally from Rietveld refinements against data from the samples with very similar composition (experimental data for $\mathrm{CeAg}_{0.8} \mathrm{SO}$ are also included for comparison). Overall, the calculated parameters are in good agreement with those determined experimentally.

Both $\mathrm{LiCeSO}$ and $\mathrm{CeSO}$ contain $\mathrm{CeO}$ layers which are fragments of the fluorite structure. They are also commonly described as PbO-type layers. In LiCeSO (Figure 9b), these $\mathrm{CeO}$ layers alternate with anti-PbO-type $\mathrm{LiS}$ layers. The $\mathrm{Li}$ and $\mathrm{O}$ ions are thus four-coordinate, in distorted tetrahedral environments, while the $\mathrm{Ce}$ and $\mathrm{S}$ atoms are both in eightcoordinate sites which can be described as distorted square antiprisms (with the parallel square faces having areas in the ratio $2: 1)$.

The CeSO structure (Figure 9a) is related to that of $\mathrm{LiCeSO}$ by removal of the layer of $\mathrm{Li}^{+}$ions and collapse of the structure along the $c$ direction. The results of magnetometry measurements show that this results in oxidation of $\mathrm{Ce}^{3+}$ to $\mathrm{Ce}^{4+}$ rather than the oxidation of sulfide, and this is confirmed by the calculations of the electronic structure described below. In the
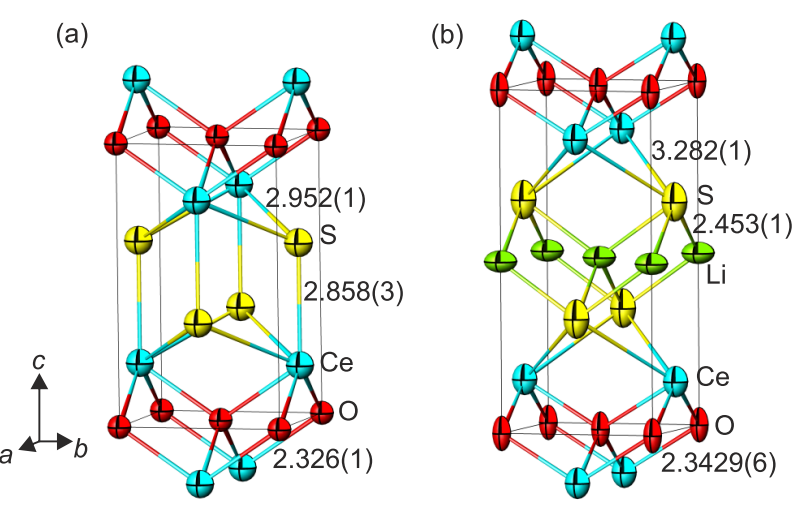

Figure 9. Crystal structures of (a) CeSO and (b) LiCeSO. Ce, Li, S, and $\mathrm{O}$ are represented by cyan, green, yellow, and red spheres, respectively. Displacement ellipsoids (anisotropic for LiCeSO and isotropic for $\mathrm{CeSO}$ in view of the stacking faults) and bond distances (in $\AA$ ) are given for refinements against PND data.

transformation from $\mathrm{LiCeSO}$ to $\mathrm{CeSO}$, the coordination number of Ce increases from 8 to 9 with the formation of a further $\mathrm{Ce}-\mathrm{S}$ bond (2.858(3) $\AA$ ) parallel to the $c$ axis so that the Ce coordination environment describes an irregular square antiprism with the larger square face capped by sulfide. With the loss of the $\mathrm{Li}$ ions, the sulfide ion becomes five-coordinate by $\mathrm{Ce}$ ions which describe a square-based pyramid. The four $\mathrm{Ce}-\mathrm{S}$ bonds present in LiCeSO also contract significantly in CeSO partly as a consequence of the oxidation of $\mathrm{Ce}^{3+}$ to $\mathrm{Ce}^{4+}$, but presumably mainly in response to the decrease in the coordination number of sulfide. The loss of the short $\mathrm{Li}-\mathrm{S}$ bonds with the deintercalation of $\mathrm{Li}$ results in a small expansion in the basal lattice vectors, presumably to optimize the $\mathrm{Ce}-\mathrm{S}$ and $\mathrm{Ce}-\mathrm{O}$ bonding.

Electronic Structure and Bonding. The presence of an unpaired f-electron on the $\mathrm{Ce}^{3+}$ ions in $\mathrm{LiCeSO}$ results in the possibility of different magnetic structures for this compound. In the simulation of the structure of $\mathrm{LiCeSO}$, two different magnetic structures were attempted: a ferromagnetic structure, with all spins aligned in the same direction, and an "A-type" antiferromagnetic solution, where ferromagnetic $a b$ sheets of $\mathrm{Ce}^{3+}$ moment ions alternate between up and down spin along the $c$ vector. Although the ferromagnetic configuration was found to have the lowest absolute energy, the difference was very small $\left(0.30 \times 10^{-3} \mathrm{eV}\right)$. For ease of analysis, all results and discussion on $\mathrm{LiCeSO}$ are therefore made from the 
(a)

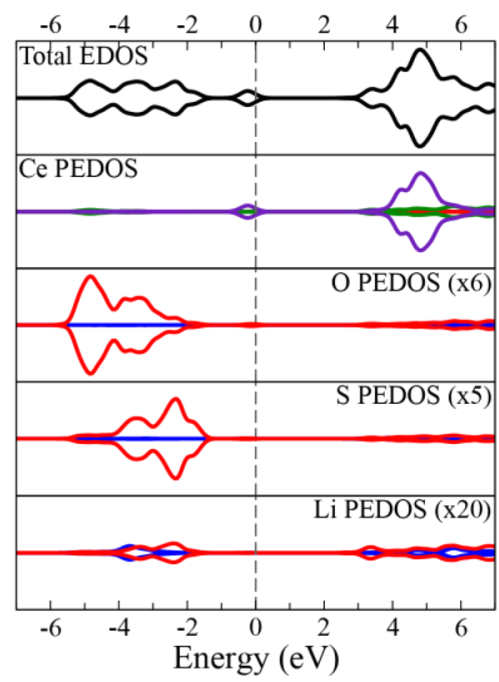

(b)

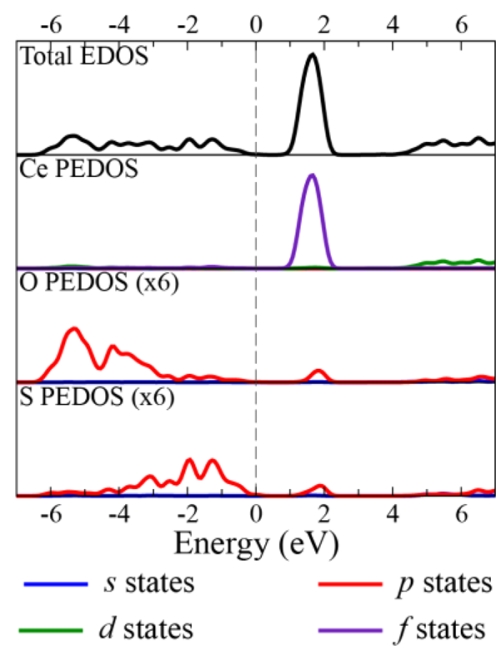

Figure 10. Electronic density of states (EDOS) and partial density of states (PEDOS) for (a) LiCeSO (decomposed into up and down spin densities of states) and (b) CeSO. The highest occupied state is set to $0 \mathrm{eV}$.

antiferromagnetic phase. We note that our experimental analysis shows no magnetic ordering transition in $\mathrm{LiCeSO}$ down to $5 \mathrm{~K}$.

The HSE06-calculated total and partial (ion and $l$ - and $m$ quantum number decomposed) electronic densities of states (EDOS/PEDOS) for the two materials are given in Figure 10.

For $\mathrm{LiCeSO}$, the top of the valence band is composed of $\mathrm{Ce}$ 4f-states resulting from the unpaired f-electron. Below this peak is a separation of $\sim 0.9 \mathrm{eV}$ to the top of the next band. This contains contributions from both $\mathrm{O}$ and $\mathrm{S}$, with the $\mathrm{S}$ states higher in energy, and hence closer to the valence band maximum (VBM), than O. Li states also appear within this region; however, due to the high electropositivity of $\mathrm{Li}$, the electron density is extremely small, so they make a minor contribution to the DOS. The bottom of the conduction band which is separated by about $3 \mathrm{eV}$ from the occupied Ce $4 \mathrm{f}$ states is primarily composed of a combination of Ce $4 \mathrm{f}$-states and $\mathrm{O} / \mathrm{S}$ p-states. These unoccupied $4 \mathrm{f}$-states are higher in energy due to shielding by the occupied 4 f-electron which results in them appearing in the band structure with the rest of the unoccupied states.

The PEDOS of CeSO are similar to those for $\mathrm{LiCeSO}$, with the exception of the Ce $4 \mathrm{f}$-states. The calculations suggest the $\mathrm{Ce}(\mathrm{IV})$ oxidation state in $\mathrm{CeSO}$ with all the $4 \mathrm{f}$-states unoccupied, and therefore resident in the conduction band (CB). This is consistent with the experimental observation that the magnetic moment of the sample of composition close to $\mathrm{CeSO}$ is only about $8 \%$ of the value expected for a $\mathrm{Ce}^{3+}$ compound with evidence that it arises from an inhomogeneous slight nonstoichiometry as discussed above. The top of the valence band in CeSO is made up of $\mathrm{O}$ and $\mathrm{S}$ p-states, with the latter forming the VBM. In comparison to the equivalent region in $\mathrm{LiCeSO}$, there is a little more peak definition in $\mathrm{CeSO}$ and the region itself is much wider in energy. The unoccupied Ce 4f-states in CeSO appear as a single broad peak and lie at a slightly lower energy compared with the LiCeSO case since there are no occupied $4 \mathrm{f}$-states to shield them from the Ce nuclear charge. Some mixing with unoccupied O/S pstates is also observed.
Bader charges were calculated for the different species and are listed in Table 4. Comparison between calculated values for

Table 4. Bader Charges for All Ions in CeSO and $\mathrm{LiCeSO}^{a}$

$\begin{array}{lccccc}\text { material } & \mathrm{Li} / \mathrm{Cu} & \mathrm{Ce}(\mathrm{III}) & \mathrm{Ce}(\mathrm{IV}) & \mathrm{O} & \mathrm{S} \\ \mathrm{LiCeOS} & 0.84 & 2.09 & & -1.36 & -1.57 \\ \mathrm{CuCeOS} & 0.40 & 2.08 & & -1.36 & -1.13 \\ \mathrm{CeOS} & & & 2.28 & -1.23 & -1.04 \\ \mathrm{CeO}_{2} & & & 2.44 & -1.22 & \end{array}$

${ }^{a}$ Calculated values for $\mathrm{CuCeSO}$ and $\mathrm{CeO}_{2}$ are included for comparison.

$\mathrm{LiCeSO}$ and for stoichiometric $\mathrm{CeCuSO}^{1}$ shows that the Ce and $\mathrm{O}$ species have similar charges in the two compounds. However, the Bader charges calculated for the $\mathrm{S}$ ions in the two compounds, -1.57 and -1.13 for $\mathrm{LiCeSO}$ and $\mathrm{CuCeSO}$, respectively, differ substantially, consistent with the difference in the charges calculated for the $\mathrm{M}(\mathrm{I})$ species: $\mathrm{Li}$ in $\mathrm{LiCeSO}$ has a Bader charge of 0.84 , close to the fully ionic charge of 1.00 , while $\mathrm{Cu}$ in $\mathrm{CeCuSO}$ has a Bader charge of 0.40 . This shows that the replacement of the coinage metal by $\mathrm{Li}$ results in a much more ionic sulfide layer.

The presence of $\mathrm{Ce}^{4+}$ ions in $\mathrm{CeSO}$ gives rise to different charges from those calculated for $\mathrm{LiCeSO}$. The $\mathrm{Ce}$ atoms themselves have a higher charge, as expected. The charges of $\mathrm{O}$ and $\mathrm{S}$ are calculated to be smaller than those in LiCeSO, suggesting that the $\mathrm{Ce}-\mathrm{O}$ and $\mathrm{Ce}-\mathrm{S}$ bonds have more covalent character in $\mathrm{CeSO}$. Comparison between $\mathrm{CeSO}$ and $\mathrm{CeO}_{2}$ shows that although the $\mathrm{O}$ atoms have similar Bader charges in the two materials, the $\mathrm{Ce}$ ions in $\mathrm{CeSO}$ have a lower Bader charge than those in $\mathrm{CeO}_{2}$, consistent with greater covalency in the $\mathrm{Ce}-\mathrm{S}$ bonds than in the $\mathrm{Ce}-\mathrm{O}$ bonds.

Band Structures. The HSE06-calculated band structures along the high-symmetry points ${ }^{62}$ for both $\mathrm{CeSO}$ and LiCeSO are shown in Figure 11 . $\mathrm{LiCeSO}$ is calculated to have an indirect band gap of $2.51 \mathrm{eV}$, with the VBM observed at the $\mathrm{A}$ point $(1 / 2,1 / 2,1 / 2)$ and the conduction band minimum $(\mathrm{CBM})$ at $\Gamma(0,0,0)$. The smallest direct fundamental band gap is located at $(0.398,0.398,0.000)$ which is offset from $M$ 
(a)

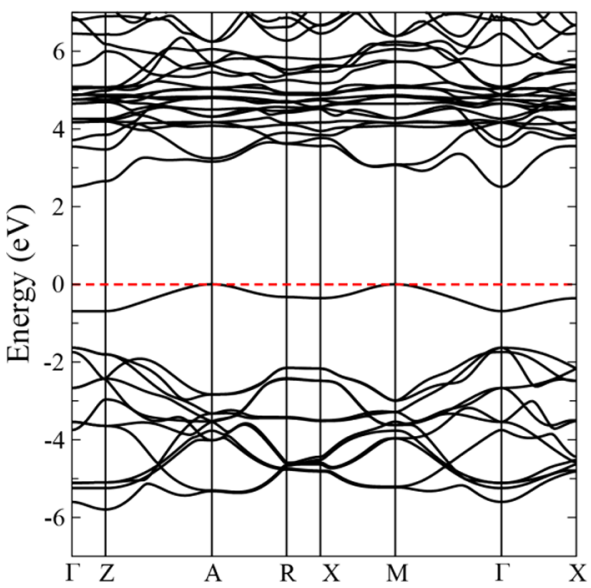

(b)

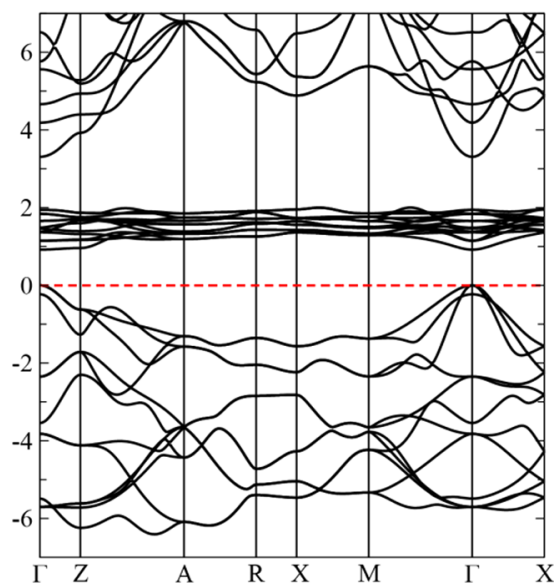

Figure 11. Electronic band structures for $\mathrm{LiCeSO}$ and $\mathrm{CeSO}$. The highest occupied state for each material is set to $0 \mathrm{eV}$, as indicated by the dashed red line.

in the $\Gamma$ direction with an energy of $3.01 \mathrm{eV}$. Conversely, $\mathrm{CeSO}$ is calculated to be a direct band gap material, with a fundamental gap of $0.92 \mathrm{eV}$ at the $\Gamma$ point.

The band structures reflect the differences in the PEDOS, with the movement of the occupied 4f-band in LiCeSO into the conduction band in $\mathrm{CeSO}$, and the increase in bandwidth of the occupied $\mathrm{O} / \mathrm{S}$ p-states. For LiCeSO, the occupied Ce $4 \mathrm{f}$ band is seen to be split off from the $\mathrm{O} / \mathrm{S}$ p-band, as observed in the PEDOS. On oxidation to $\mathrm{CeSO}$, when the $4 \mathrm{f}$-states become unoccupied, these states all lie in the range $1-2 \mathrm{eV}$ above the VBM.

The change in VBM and CBM character will have consequences for the conduction properties of the two materials. LiCeSO has a relatively flat VBM composed of Ce $4 \mathrm{f}$-states, and a more dispersive CBM indicating that mobility for n-type conductivity will be higher; however, with $\mathrm{Ce}^{3+}$ already present, the formation of such charge carriers will be difficult. In CeSO where the dispersion of the VBM makes ptype conductivity more favorable, the formation of hole charge carriers by partial oxidation of sulfide might be plausible. The conductivities of these compounds prepared by soft chemical approaches are difficult to measure experimentally because the compounds are not stable to sintering attempts.

The calculated optical absorption spectra are shown in Figure S14. The analysis gives calculated optical band gaps ${ }^{63}$ of 1.5 and $3.6 \mathrm{eV}$ for CeSO and LiCeSO, respectively.

Electrochemistry of LiCeSO and CeSO. Figure 12a shows the discharge profile for a cell composed of a positive electrode containing the sample close in composition to CeSO (obtained by direct deintercalation of $\mathrm{Ag}$ from $\mathrm{CeAg}_{0.8} \mathrm{SO}$ ) and a $\mathrm{Li}$ metal negative electrode recorded during an in situ PXRD measurement carried out at a rate of $\mathrm{C} / 30$ (i.e., full discharge over a period of $30 \mathrm{~h}$ ). Cycling results obtained at a $\mathrm{C} / 10$ rate are shown in Figure S15. Discharge of the cells shows a plateau at about $2 \mathrm{~V}$ (vs the $\mathrm{Li}^{+} / \mathrm{Li}$ couple), suggestive of a two-phase region which is confirmed by the in situ PXRD measurements (Figure 12b); the specific capacity on discharging the cell to $0.7 \mathrm{~V}$ corresponds closely to the $142 \mathrm{mAhr} \mathrm{g}^{-1}$ expected for the intercalation of $\mathrm{Li}$ into $\mathrm{CeSO}$ to produce $\mathrm{LiCeSO}$. The X-ray diffractogram (Figure 13b) of the sample extracted from a fully discharged cell (discharged to $0 \mathrm{~V}$ vs $\mathrm{Li}^{+} / \mathrm{Li}$ ) corresponds quantitatively to $\mathrm{LiCeSO}$, and the diffractograms of the electrode material before (Figure 13a) and after discharge

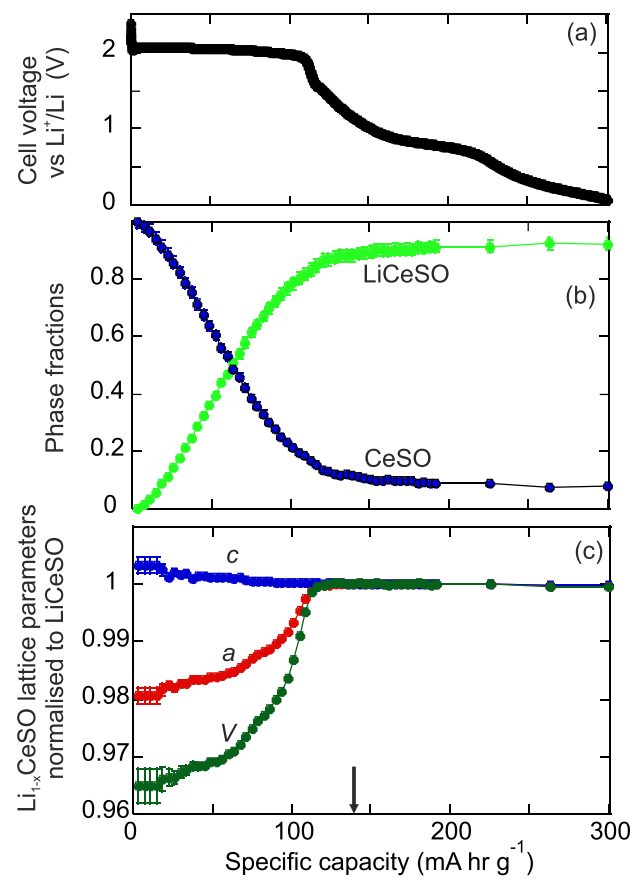

Figure 12. Results of X-ray diffraction measurements collected during in situ first discharge of an electrochemical cell composed of a CeSO positive electrode and a Li negative electrode: (a) the electrochemical profile, (b) the refined phase fractions of the CeSO phase and the $\mathrm{Li}_{1-x} \mathrm{CeSO}$ phase formed in the reaction, and (c) the evolution of the lattice parameters and cell volume of the $\mathrm{Li}_{1-x} \mathrm{CeSO}$ phase normalized to the values for $\mathrm{LiCeSO}$. The arrow indicates the specific capacity for the insertion of $1 \mathrm{~mol}$ of $\mathrm{Li}$ into $1 \mathrm{~mol}$ of CeSO.

(Figure 13b) emphasize the improvement in crystallinity on intercalation to produce $\mathrm{LiCeSO}$, consistent with the presence of stacking faults in CeSO. Rietveld analysis of the diffractograms obtained during the in situ PXRD measurement show that two phases are present and that a phase with lattice parameters similar to those of $\mathrm{LiCeSO}$ increases in phase fraction at the expense of the $\mathrm{CeSO}$ phase. The lattice parameters of the LiCeSO-like phase were found to evolve during the conversion (Figure 12c), in particular the basal lattice parameter $a$ increases significantly during the plateau in the voltage profile, suggesting the formation of a range of 


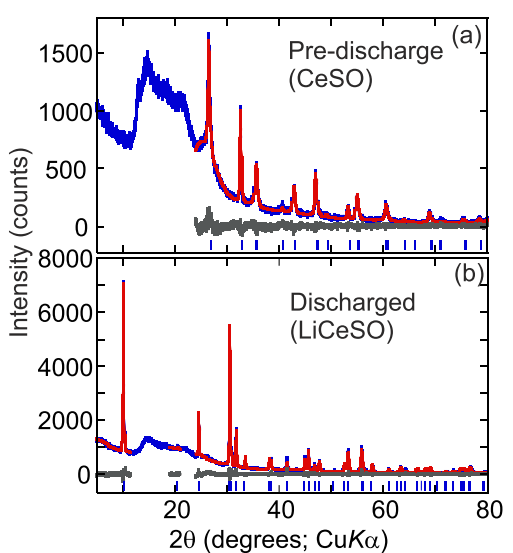

Figure 13. X-ray diffractograms of the positive electrode composite containing CeSO (a) before discharge (the Rietveld fit is to the structural model for CeSO) and (b) after discharge of the cell to $0 \mathrm{~V}$ $\mathrm{vs}^{\mathrm{Li}^{+}} / \mathrm{Li}$ (the Rietveld fit is to the structural model for $\mathrm{LiCeSO}$ ). Note the increase of crystallinity that occurs on intercalation. Lowangle regions containing background contributions from the other components of the electrode material were excluded from the refinements. Data (blue), fit (red), and difference (gray) are shown. Tick marks for the relevant phases in each case are also shown.

$\mathrm{Li}_{1-x} \mathrm{CeSO}$ phases during the reduction process, with full lithiation coinciding with the voltage drop at the end of the plateau in the voltage profile. By comparing the variation in unit cell volume with that found for $\mathrm{CeCu}_{1-x} \mathrm{SO}$ phases ${ }^{1}$ we estimate that $\mathrm{Li}_{1-x} \mathrm{CeSO}$ phases with $0<x<0.2$ are formed during the intercalation of $\mathrm{Li}$ into $\mathrm{CeSO}$. This observation of a change in composition is consistent with the ${ }^{6} \mathrm{Li} \mathrm{NMR}$ data collected during the first discharge of the cell (Figure 14) which show not only an increase in the intensity of the ${ }^{6} \mathrm{Li}$ resonance as $\mathrm{Li}$ is inserted, but also an increasing paramagnetic shift of the resonance in the two-phase region which continues beyond the plateau in the voltage profile. The shift, which is presumably due to the presence of the paramagnetic $\mathrm{Ce}^{3+}$ centers, reaches a maximum when the cell has been discharged to $0.7 \mathrm{~V}$, i.e., just below the sharp step in the voltage profile and consistent with the expected capacity for intercalation of 1 mol of $\mathrm{Li}$ per mole of $\mathrm{CeSO}$, and discharging to $0 \mathrm{~V}$ does not result in a further shift in the resonance suggesting that $\mathrm{Ce}$ is fully reduced to $\mathrm{Ce}^{3+}$ at $0.7 \mathrm{~V}$. The paramagnetic shift of -95 ppm in fully reduced $\mathrm{LiCeSO}$ is ascribed to the Fermi contact interaction of the Li nuclear spins with unpaired spin density of the $\mathrm{Ce}^{3+}$ ions. Each $\mathrm{Li}$ ion is involved with 12 neighboring $\mathrm{Ce}^{3+}$ ions via $16 \mathrm{Ce}-\mathrm{S}-\mathrm{Li}$ interactions. For contrast, in the series $\mathrm{Sr}_{2} \mathrm{MnO}_{2} \mathrm{Li}_{2 m} \mathrm{~S}_{m+1}(m=1,2,3)$, the paramagnetic shift of the ${ }^{6} \mathrm{Li}$ resonance in lithium sulfide layers was determined to be approximately $100 \mathrm{ppm}$ for each $\mathrm{Mn}^{2+}$ ion engaged in a rather weak covalent interaction $\mathrm{Mn}-\mathrm{S}-\mathrm{Li}$ via long $\mathrm{Mn}-\mathrm{S}$ bonds. ${ }^{47}$ The order-of-magnitude-smaller shift per neighboring $\mathrm{Ce}^{3+}$ ion in LiCeSO presumably reflects the weak covalency of the interactions between not only the Li 2 s- and S 3p-states, but also between the Ce $4 \mathrm{f}$ - and S 3p-states. This is consistent with the computational results and chemical expectations.

Comparison of the Soft Chemistry of $\mathrm{CeAg}_{0.8} \mathrm{SO}$ and $\mathrm{CeCu}_{0.8} \mathrm{SO}$. $\mathrm{CeCu}_{0.8} \mathrm{SO}$ was also synthesized and used as a precursor for soft chemical transformations in order to make a comparison with the $\mathrm{Ag}$ analogue of similar coinage metal composition. The lithiations of both $\mathrm{CeCu}_{0.8} \mathrm{SO}$ and $\mathrm{CeAg}_{0.8} \mathrm{SO}$ at ambient temperature using $n$-BuLi both produced clear color changes. The black Ag-containing precursor $\mathrm{CeAg}_{0.8} \mathrm{SO}$ yielded a highly air-sensitive powder of a dark-green color (a mixture of elemental $\mathrm{Ag}$ and $\mathrm{LiCeSO}$ as described above). The black $\mathrm{Cu}$-containing precursor $\mathrm{CeCu}_{0.8} \mathrm{SO}$ yielded an extremely air-sensitive light-brown/ yellow powder which turned black within seconds on air exposure. In contrast to the Ag case, laboratory PXRD showed the product of lithiation of the $\mathrm{Cu}$ precursor to be single-phase, retaining the $\mathrm{ZrCuSiAs}$ structure with a unit cell volume of 135.870 (4) $\AA^{3}$ that was $5.0 \%$ larger than that of $\mathrm{CeCu}_{0.8} \mathrm{SO}$ (129.448(4) $\left.\AA^{3}\right)$, and which exceeded the cell volume of $132.405 \AA^{3}$ found for the fully stoichiometric $\mathrm{CeCuSO},{ }^{1}$ although it was significantly smaller than the volume of 138.075(1) $\AA^{3}$ found for LiCeSO obtained by the analogous reaction with $\mathrm{CeAg}_{0.8} \mathrm{SO}$ and described above.

Analysis of the diffraction data for the lithiated product (Figure 15 and Figure S16; Table S3) showed that lithium had been inserted to fill the vacant sites in the sulfide layers. However, there was no evidence for the measurable extrusion of elemental $\mathrm{Cu}$ from the powder patterns of the lithiated products. This is in stark contrast to the coinage metal extrusion that occurs with the $\mathrm{CeAg}_{0.8} \mathrm{SO}$ precursor and with

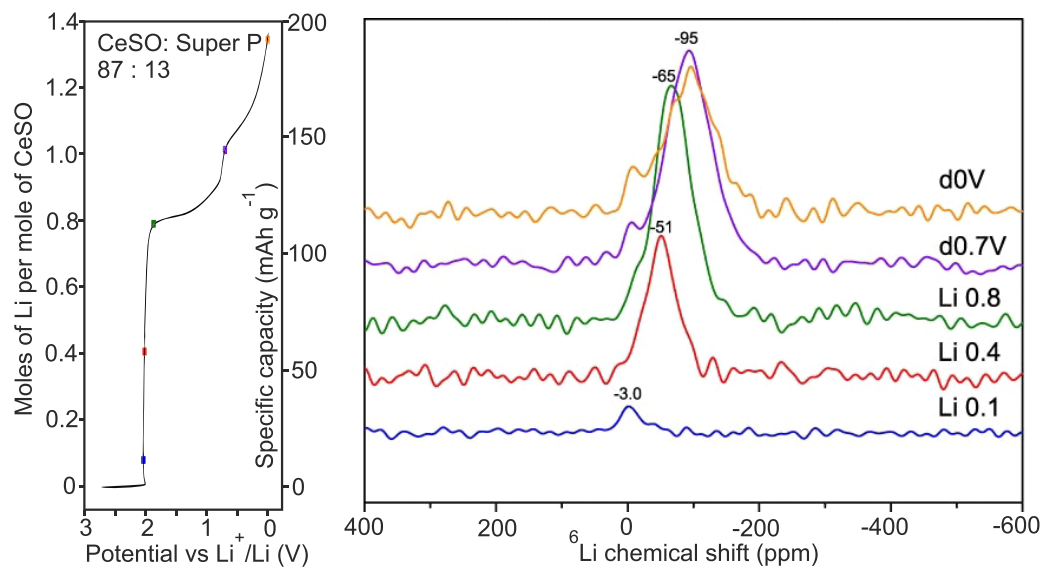

Figure 14. Shift of the ${ }^{6} \mathrm{Li}$ NMR measurements made during cell discharge. The shift of the resonance is consistent with the changing composition of the intercalation product evident from the in situ PXRD measurements (Figure 12). The electrochemical profile corresponding to this experiment is also shown. 


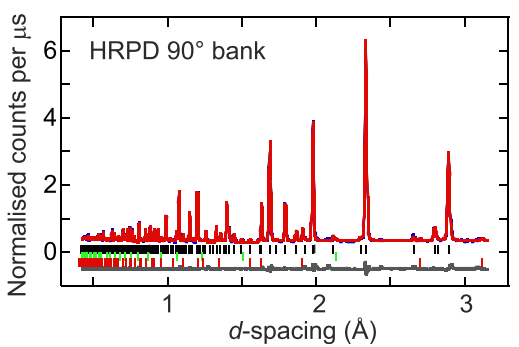

Figure 15. Rietveld refinements against PND data (HRPD $90^{\circ}$ bank shown) for $\mathrm{Li}_{0.2} \mathrm{CeCu}_{0.8} \mathrm{SO}$. Data (blue), fit (red), and difference (gray) are shown. Tick marks for the main phase (upper), V sample holder (middle), and a small $\mathrm{CeO}_{2}$ impurity ( $1.8 \%$ by mass) (lower) are shown. Further fits and refinement parameters are provided as Supporting Information (Figure S16 and Table S3).

the series of layered oxide chalcogenides $\mathrm{Sr}_{2} \mathrm{MnO}_{2} \mathrm{Cu}_{2 m-0.5} \mathrm{~S}_{m+1}$ $(m=1,2,3)$ with similarly $\mathrm{Cu}$-deficient sulfide layers. ${ }^{46,4}$ Refinement against PND data from HRPD (Figure 15 and Figure S16) confirmed that in the lithiation product of $\mathrm{CeCu}_{0.8} \mathrm{SO}$ the $\mathrm{Cu}$ occupancy was unchanged from that in the precursor and that within the experimental uncertainty the remaining sites in the sulfide layer were completely filled by $\mathrm{Li}$ ions producing $\mathrm{Li}_{0.2} \mathrm{CeCu}_{0.8} \mathrm{SO}$. A full description of the structure of this compound is included in Table S3.

We propose that the difference in behavior between $\mathrm{CeCu}_{0.8} \mathrm{SO}$ and $\mathrm{CeAg}_{0.8} \mathrm{SO}$, where only the coinage metal cation changes, arises in part from the larger separation of adjacent sulfide layers in the $\mathrm{Ag}$ case: in order to accommodate the larger $\mathrm{Ag}^{+}$ion the $\mathrm{S}-\mathrm{S}$ separations between adjacent slabs of composition $\mathrm{CeSO}$ must increase, but in the basal direction they are constrained to change very little as the basal lattice parameters are constrained by the geometry of the $\mathrm{CeO}$ layers. Thus, $\mathrm{Ag}$ in $\mathrm{CeAg}_{0.8} \mathrm{SO}$ is in a $\mathrm{AgS}_{4}$ tetrahedron that is highly distorted (two S-Ag-S angles of $94.9^{\circ}$ and four of $\left.117.2^{\circ}\right)^{2}$ and which is relatively extended in the direction parallel to the c lattice vector compared with the almost regular $\mathrm{CuS}_{4}$ tetrahedron in $\mathrm{CeCu}_{0.8} \mathrm{SO}$ (two $\mathrm{S}-\mathrm{Cu}-\mathrm{S}$ angles of $108.8^{\circ}$ and four of $\left.109.8^{\circ}\right)^{2}$ as also discussed elsewhere. ${ }^{64}$ This likely enhances the mobility of $\mathrm{Ag}^{+}$ions compared with the $\mathrm{Cu}^{+}$ions in $\mathrm{CeCu}_{0.8} \mathrm{SO}$, in line with the observations that the activation barrier for $\mathrm{Ag}^{+}$motion in LaAgSO which is reported as 0.195 $\mathrm{eV}^{65}$ or $0.22 \mathrm{eV}^{5}$ is significantly smaller than that reported for $\mathrm{Cu}^{+}(0.32 \mathrm{eV})$ in the analogue LaCuSO. ${ }^{66}$

\section{CONCLUSIONS}

We have shown that the high mobility of coinage metal ions, particularly $\mathrm{Ag}^{+}$, in layered oxide sulfides enables soft chemical transformations to be performed. Oxidative topotactic deintercalation of $\mathrm{Ag}$ from $\mathrm{CeAg}_{0.8} \mathrm{SO}$ produces a metastable compound with a composition approaching $\mathrm{CeSO}$ with oxidation of $\mathrm{Ce}$ to the +4 oxidation state, which in turn acts as an intercalation host for $\mathrm{Li}$, leading reversibly to $\mathrm{LiCeSO}$ using chemical or electrochemical methods. While the results of computational analysis on stoichiometric CeSO show that the Ce 4f-states lie completely above the Fermi level, magnetometry measurements show a significant remaining Curie paramagnetism which we ascribe to a few percent of residual $\mathrm{Ce}^{3+}$ moments consistent with the structural analysis of CeSO using high-resolution PXRD and PND and TEM which reveal stacking faults which are best modeled as arising from incomplete removal of $\mathrm{Ag}$ ions at the level of about 5\% with the result that some paramagnetic $\mathrm{Ce}^{3+}$ ions remain.
CeSO with the PbFCl-type structure is isostructural with the compounds ThSO, USO, and NpSO reported from powder data collected in the $1940 \mathrm{~s},{ }^{51}$ and with the recently reported polymorph of $\mathrm{ZrSO}$ obtained pure by high-pressure synthesis. ${ }^{53}$ The early reports do not describe any anomalies in the appearance of the powder patterns such as anisotropic peak broadening, although, if present, these might not have been evident in the data collected. The tetragonal $\mathrm{ZrSO}$ phase ${ }^{53}$ shows no evidence for such broadening. The clear presence of faulting in the structure of $\mathrm{CeSO}$ may reflect the difficulty of stabilizing this high oxidation state of +4 for $\mathrm{Ce}$ in the presence of sulfide, and it may also be a consequence of the synthetic method, but the failure to completely remove all the coinage metal from the original $\mathrm{CeAg}_{0.8} \mathrm{SO}$ precursor has precedent (e.g., in the chemistry of $\left.\mathrm{CuZr}_{2} \mathrm{~S}_{4}\right) .{ }^{49}$ While the calculations of the band structure presented here show that in the idealized CeSO composition a bona fide $\mathrm{Ce}^{4+}$ species is attainable in the presence of a mixture of oxide and sulfide ions, reliable crystallographic investigations of pure sulfides of Ce which are more sulfide-rich than $\mathrm{Ce}_{2} \mathrm{~S}_{3}$ show that these invariably contain oxidized anions $\left[\mathrm{S}_{2}\right]^{2-}$. These include $\mathrm{CeS}_{1.9}$ and two polymorphs of $\mathrm{CeS}_{2}$ in which $\mathrm{S}-\mathrm{S}$ distances in the $\left[\mathrm{S}_{2}\right]^{2-}$ anions are similar, within the uncertainties, to those found for the analogous compounds with the less oxidizable light lanthanides at 2.154(8) $\AA$ for $\alpha-\mathrm{CeS}_{2}$ and 2.115(3) for $\beta$ $\mathrm{CeS}_{2},{ }^{67}$ distances characteristic of $\left[\mathrm{S}_{2}\right]^{2-}$ anions (cf., 2.103(3) $\AA$ in the $\left[\mathrm{S}_{2}\right]^{2-}$ ions of LaSO). ${ }^{56}$ Thus, $\mathrm{Ce}^{4+}$ readily oxidizes sulfide, and this may reflect the difficulty in completely deintercalating all the $\mathrm{Ag}$ from $\mathrm{CeAg}_{0.8} \mathrm{SO}$ to obtain pure $\mathrm{CeSO}$. In contrast, $\mathrm{CeSO}$, with no $\mathrm{S}-\mathrm{S}$ contacts shorter than $3.23 \AA$, resembles other systems with only monosulfide ions, e.g., $\mathrm{ZrS}_{2}$ with no $\mathrm{S}-\mathrm{S}$ contacts shorter than $3.59 \AA \mathrm{a} \mathrm{Zr}^{4+}$ compound with six-coordinate $\mathrm{Zr}$ in the $\mathrm{CdCl}_{2}$ structure type), ${ }^{68}$ and $\mathrm{ThS}_{2}$ with no $\mathrm{S}-\mathrm{S}$ contacts shorter than $3.19 \AA$ (a $\mathrm{Th}^{4+}$ compound with nine-coordinate $\mathrm{Th}$ in the $\mathrm{PbCl}_{2}$ structure type). ${ }^{69}$ However, the evident difficulty in stabilizing $\mathrm{Ce}^{4+}$ in the presence of $\mathrm{S}^{2-}$ anions may be the origin of the defective structure of $\mathrm{CeSO}$.

\section{ASSOCIATED CONTENT}

\section{Supporting Information}

The Supporting Information is available free of charge on the ACS Publications website at DOI: 10.1021/acs.inorgchem. 8 b03485.

Analysis of intrinsic Ag-deficiency of "CeAgSO samples", further Rietveld refinements, further description of the stacking fault models, further electron diffraction and microscopy images, further plots of the magnetic data, calculations of optical properties, results of electrochemical cycling, and structural analysis of $\mathrm{Li}_{0.2} \mathrm{Ce}$ $\mathrm{Cu}_{0.8} \mathrm{SO}(\mathrm{PDF})$

\section{AUTHOR INFORMATION}

\section{Corresponding Author}

*E-mail: simon.clarke@chem.ox.ac.uk.

ORCID ${ }^{\circ}$

Joke Hadermann: 0000-0002-1756-2566

Graeme W. Watson: 0000-0001-6732-9474

Clare P. Grey: 0000-0001-5572-192X

Simon J. Clarke: 0000-0003-4599-8874 


\section{Author Contributions}

M.J.P., J.J.K.L., and E.J.C. prepared the samples and, with D.G.F, performed preliminary structural analyses and magnetometry measurements. S. J. Cassidy performed the detailed analysis of the diffraction measurements. J.H. performed and analyzed the electron microscopy measurements. J.P.A. and G.W.W. performed and interpreted the computational analysis. S.B. performed the electrochemical experiments and NMR measurements in the group of C.P.G., with some of these results analyzed by S. J. Clarke. S. J. Clarke conceived the project and, with S. J. Cassidy, wrote the paper. Overall, all authors made contributions of approximately equal importance.

\section{Notes}

The authors declare no competing financial interest.

\section{ACKNOWLEDGMENTS}

We thank the UK EPSRC (EP/M020517/1 and EP/P018874/ 1), the Leverhulme Trust (RPG-2014-221), and Science Foundation Ireland (Grant 12/IA/1414) for funding and the EPSRC for additional studentship support. We acknowledge the ISIS pulsed neutron and muon source and the Diamond Light Source Ltd. (EE13284 and EE18786) and the ESRF for the award of beam time. We thank Dr. R. I. Smith for assistance on the neutron beamlines, Dr. A. Baker and Dr. C. Murray for support on I11, and Dr. C. Curfs for support on ID31.

\section{REFERENCES}

(1) Pitcher, M. J.; Smura, C. F.; Clarke, S. J. Stoichiometric CeCuOS - A Well-Behaved Ce(III) Layered Oxysulfide. Inorg. Chem. 2009, 48, 9054-9056.

(2) Chan, G. H.; Deng, B.; Bertoni, M.; Ireland, J. R.; Hersam, M. C.; Mason, T. O.; Van Duyne, R. P.; Ibers, J. A. Syntheses, Structures, Physical Properties, and Theoretical Studies of $\mathrm{CeM}_{x} \mathrm{OS}(\mathrm{M}=\mathrm{Cu}$, $\mathrm{Ag} ; x \approx 0.8)$ and CeAgOS. Inorg. Chem. 2006, 45, 8264-8272.

(3) Hiramatsu, H.; Kamihara, Y.; Yanagi, H.; Ueda, K.; Kamiya, T.; Hirano, M.; Hosono, H. Layered mixed-anion compounds: Epitaxial growth, active function exploration, and device application. J. Eur. Ceram. Soc. 2009, 29, 245-253.

(4) Kamihara, Y.; Watanabe, T.; Hirano, M.; Hosono, H. Iron-based layered superconductor $\mathrm{La}\left[\mathrm{O}_{1-x} \mathrm{~F}_{x}\right] \mathrm{FeAs}(x=0.05-0.12)$ with $\mathrm{T}_{\mathrm{c}}=$ 26 K. J. Am. Chem. Soc. 2008, 130, 3296-3297.

(5) Wilmer, D.; Jorgensen, J. D.; Wuensch, B. J. Two-dimensional silver fast-ion conduction in (LaO)AgS. Solid State Ionics 2000, 136137, 961-966.

(6) Clarke, S. J.; Adamson, P.; Herkelrath, S. J. C.; Rutt, O. J.; Parker, D. R.; Pitcher, M. J.; Smura, C. F. Structures, Physical Properties, and Chemistry of Layered Oxychalcogenides and Oxypnictides. Inorg. Chem. 2008, 47, 8473-8486.

(7) Poettgen, R.; Johrendt, D. Materials with ZrCuSiAs-type Structure. Z. Naturforsch., B: J. Chem. Sci. 2008, 63, 1135-1148.

(8) Smura, C. F.; Parker, D. R.; Zbiri, M.; Johnson, M. R.; Gál, Z. A.; Clarke, S. J. High-Spin cobalt(II) ions in square planar coordination: Structures and magnetism of the oxysulfides $\mathrm{Sr}_{2} \mathrm{CoO}_{2} \mathrm{Cu}_{2} \mathrm{~S}_{2}$ and $\mathrm{Ba}_{2} \mathrm{CoO}_{2} \mathrm{Cu}_{2} \mathrm{~S}_{2}$ and their solid solution. J. Am. Chem. Soc. 2011, 133, 2691-2705.

(9) Blandy, J. N.; Abakumov, A. M.; Christensen, K. E.; Hadermann, J.; Adamson, P.; Cassidy, S. J.; Ramos, S.; Free, D. G.; Cohen, H.; Woodruff, D. N.; Thompson, A. L.; Clarke, S. J. Soft chemical control of the crystal and magnetic structure of a layered mixed valent Manganite oxide sulfide. APL Mater. 2015, 3, 041520.

(10) Komatsuzaki, S.; Takase, K.; Smura, C. F.; Takahashi, Y.; Takano, Y.; Sekizawa, K.; Clarke, S. J. Synthesis and the crystal structure of $\mathrm{CeCuS}_{2}$. J. Alloys Compd. 2006, 408-412, 586-588.
(11) Thompson, S. P.; Parker, J. E.; Potter, J.; Hill, T. P.; Birt, A.; Cobb, T. M.; Yuan, F.; Tang, C. C. Beamline I11 at Diamond: A new instrument for high resolution powder diffraction. Rev. Sci. Instrum. 2009, 80, 075107.

(12) Fitch, A. N. The High Resolution Powder Diffraction Beam Line at ESRF. J. Res. Natl. Inst. Stand. Technol. 2004, 109, 133-142.

(13) Hull, S.; Smith, R. I.; David, W. I. F.; Hannon, A. C.; Mayers, J.; Cywinski, R. The Polaris powder diffractometer at ISIS. Phys. B 1992, 180-181, 1000-1002.

(14) Coelho, A. A. TOPAS Academic Version 5; Coelho Software: Brisbane, Australia, 2012.

(15) Coelho, A. A.; Evans, J. S. O.; Lewis, J. W. Averaging the intensity of many-layered structures for accurate stacking-fault analysis using Rietveld refinement. J. Appl. Crystallogr. 2016, 49, 1740-1749.

(16) Kresse, G.; Furthmüller, J. Efficiency of ab-initio total energy calculations for metals and semiconductors using a plane-wave basis set. Comput. Mater. Sci. 1996, 6, 15-50.

(17) Kresse, G.; Hafner, J. Ab initio molecular-dynamics simulation of the liquid-metal-amorphous-semiconductor transition in germanium. Phys. Rev. B: Condens. Matter Mater. Phys. 1994, 49, 1425114269.

(18) Perdew, J. P.; Burke, K.; Ernzerhof, M. Generalized Gradient Approximation Made Simple [Phys. Rev. Lett. 77, 3865 (1996)]. Phys. Rev. Lett. 1997, 78, 1396-1396.

(19) Blöchl, P. E. Projector augmented-wave method. Phys. Rev. B: Condens. Matter Mater. Phys. 1994, 50, 17953-17979.

(20) Heyd, J.; Peralta, J. E.; Scuseria, G. E.; Martin, R. L. Energy band gaps and lattice parameters evaluated with the Heyd-ScuseriaErnzerhof screened hybrid functional. J. Chem. Phys. 2005, 123, 174101.

(21) Heyd, J.; Scuseria, G. E.; Ernzerhof, M. Hybrid functionals based on a screened Coulomb potential. J. Chem. Phys. 2003, 118, $8207-8215$

(22) Krukau, A. V.; Vydrov, O. A.; Izmaylov, A. F.; Scuseria, G. E. Influence of the exchange screening parameter on the performance of screened hybrid functionals. J. Chem. Phys. 2006, 125, 224106.

(23) Scanlon, D. O.; Walsh, A.; Watson, G. W. Understanding the pType Conduction Properties of the Transparent Conducting Oxide $\mathrm{CuBO}_{2}$ : A Density Functional Theory Analysis. Chem. Mater. 2009, 21, 4568-4576.

(24) Allen, J. P.; Scanlon, D. O.; Watson, G. W. Electronic structure of mixed-valence silver oxide $\mathrm{AgO}$ from hybrid density-functional theory. Phys. Rev. B: Condens. Matter Mater. Phys. 2010, 81, 161103.

(25) Heyd, J.; Scuseria, G. E. Efficient hybrid density functional calculations in solids: Assessment of the Heyd-Scuseria-Ernzerhof screened Coulomb hybrid functional. J. Chem. Phys. 2004, 121, 11871192.

(26) Marsman, M.; Paier, J.; Stroppa, A.; Kresse, G. Hybrid functionals applied to extended systems. J. Phys.: Condens. Matter 2008, 20, 064201.

(27) Chen, S.; Gong, X. G.; Walsh, A.; Wei, S.-H. Crystal and electronic band structure of $\mathrm{Cu}_{2} \mathrm{ZnSnX}_{4}(\mathrm{X}=\mathrm{S}$ and Se $)$ photovoltaic absorbers: First-principles insights. Appl. Phys. Lett. 2009, 94, 041903.

(28) Scanlon, D. O.; Watson, G. W. Conductivity Limits in $\mathrm{CuAlO}_{2}$ from Screened-Hybrid Density Functional Theory. J. Phys. Chem. Lett. 2010, 1, 3195-3199.

(29) Scanlon, D. O.; Watson, G. W. Undoped $n$-Type $\mathrm{Cu}_{2} \mathrm{O}$ : Fact or Fiction? J. Phys. Chem. Lett. 2010, 1, 2582-2585.

(30) Scanlon, D. O.; Watson, G. W. Understanding the p-type defect chemistry of $\mathrm{CuCrO}_{2}$. J. Mater. Chem. 2011, 21, 3655-3663.

(31) Stroppa, A.; Kresse, G. Unraveling the Jahn-Teller effect in Mndoped GaN using the Heyd-Scuseria-Ernzerhof hybrid functional. Phys. Rev. B: Condens. Matter Mater. Phys. 2009, 79, 201201.

(32) Da Silva, J. L. F.; Ganduglia-Pirovano, M. V.; Sauer, J.; Bayer, V.; Kresse, G. Hybrid functionals applied to rare-earth oxides: The example of ceria. Phys. Rev. B: Condens. Matter Mater. Phys. 2007, 75, 045121.

(33) Prodan, I. D.; Scuseria, G. E.; Martin, R. L. Assessment of metageneralized gradient approximation and screened Coulomb 
hybrid density functionals on bulk actinide oxides. Phys. Rev. B: Condens. Matter Mater. Phys. 2006, 73, 045104.

(34) Stroppa, A.; Picozzi, S. Hybrid functional study of proper and improper multiferroics. Phys. Chem. Chem. Phys. 2010, 12, 5405.

(35) Murnaghan, F. D. The Compressibility of Media under Extreme Pressures. Proc. Natl. Acad. Sci. U. S. A. 1944, 30, 244-247.

(36) Allen, J. P.; Scanlon, D. O.; Parker, S. C.; Watson, G. W. Tin monoxide: Structural prediction from first principles calculations with van der Waals corrections. J. Phys. Chem. C 2011, 115, 19916-19924.

(37) Tang, W.; Sanville, E.; Henkelman, G. A grid-based Bader analysis algorithm without lattice bias. J. Phys.: Condens. Matter 2009, 21,084204

(38) Gajdoš, M.; Hummer, K.; Kresse, G.; Furthmüller, J.; Bechstedt, F. Linear optical properties in the projector-augmented wave methodology. Phys. Rev. B: Condens. Matter Mater. Phys. 2006, 73, 045112 .

(39) Adolph, B.; Furthmüller, J.; Bechstedt, F. Optical properties of semiconductors using projector-augmented waves. Phys. Rev. B: Condens. Matter Mater. Phys. 2001, 63, 125108.

(40) Ramos, L. E.; Paier, J.; Kresse, G.; Bechstedt, F. Optical spectra of Si nanocrystallites: Bethe-Salpeter approach versus time-dependent density-functional theory. Phys. Rev. B: Condens. Matter Mater. Phys. 2008, 78, 195423.

(41) Paier, J.; Marsman, M.; Kresse, G. Dielectric properties and excitons for extended systems from hybrid functionals. Phys. Rev. B: Condens. Matter Mater. Phys. 2008, 78, 121201.

(42) Nie, X.; Wei, S.-H.; Zhang, S. B. Bipolar Doping and Band-Gap Anomalies in Delafossite Transparent Conductive Oxides. Phys. Rev. Lett. 2002, 88, 066405.

(43) Kehoe, A. B.; Scanlon, D. O.; Watson, G. W. Nature of the band gap of $\mathrm{Tl}_{2} \mathrm{O}_{3}$. Phys. Rev. B: Condens. Matter Mater. Phys. 2011, 83, 233202.

(44) Allen, J. P.; Nilsson, M. K.; Scanlon, D. O.; Watson, G. W. Comparison of the defective pyrochlore and ilmenite polymorphs of $\mathrm{AgSbO}_{3}$ using GGA and hybrid DFT. Phys. Rev. B: Condens. Matter Mater. Phys. 2011, 83, 035207.

(45) Scanlon, D. O.; Watson, G. W. Band gap anomalies of the $\mathrm{ZnM}_{2}{ }^{\mathrm{III}} \mathrm{O}_{4}\left(\mathrm{M}^{\mathrm{III}}=\mathrm{Co}, \mathrm{Rh}, \mathrm{Ir}\right)$ spinels. Phys. Chem. Chem. Phys. 2011, 13, 9667.

(46) Rutt, O. J.; Williams, G. R.; Clarke, S. J. Reversible lithium insertion and copper extrusion in layered oxysulfides. Chem. Commun. 2006, 2006, 2869.

(47) Indris, S.; Cabana, J.; Rutt, O. J.; Clarke, S. J.; Grey, C. P. Layered oxysulfides $\mathrm{Sr}_{2} \mathrm{MnO}_{2} \mathrm{Cu}_{2 m-0.5} S_{m+1}(m=1,2$, and 3$)$ as insertion hosts for $\mathrm{Li}$ ion batteries. J. Am. Chem. Soc. 2006, 128, 13354-13355.

(48) Robert, R.; Zeng, D.; Lanzirotti, A.; Adamson, P.; Clarke, S. J.; Grey, C. P. Scanning X-ray fluorescence imaging study of lithium insertion into copper based oxysulfides for Li-Ion batteries. Chem. Mater. 2012, 24, 2684-2691.

(49) James, A. C. W. P.; Ellis, B.; Goodenough, J. B. Lithium insertion into the normal thiospinel $\mathrm{CuZr}_{2} \mathrm{~S}_{4}$ and the defect thiospinel $\mathrm{Cu}_{0.05} \mathrm{Zr}_{2} \mathrm{~S}_{4}$. Solid State Ionics 1988, 27, 45-55.

(50) King, E. L.; Krall, H. J.; Pandow, M. L. Studies Pertaining to Soluble Silver Iodide Species. J. Am. Chem. Soc. 1952, 74, 3492-3496.

(51) Zachariasen, W. H. IUCr. Crystal chemical studies of the $5 f$ -series of elements. X. Sulfides and oxysulfides. Acta Crystallogr. 1949, 2, 291-296.

(52) Jellinek, F.; et al. A Tetragonal Form of Zirconium Oxide Sulfide, ZrOS. Acta Chem. Scand. 1962, 16, 791-792.

(53) Arai, T.; Iimura, S.; Kim, J.; Toda, Y.; Ueda, S.; Hosono, H. Chemical Design and Example of Transparent Bipolar Semiconductors. J. Am. Chem. Soc. 2017, 139, 17175-17180.

(54) Wichelhaus, W. $\mathrm{Ce}_{4} \mathrm{O}_{4} \mathrm{~S}_{3}$ ein gemischtvalentes Ceroxidsulfid. Angew. Chem. 1978, 90, 476-476.

(55) Shannon, R. D.; Prewitt, C. T. Effective ionic radii in oxides and fluorides. Acta Crystallogr., Sect. B: Struct. Crystallogr. Cryst. Chem. 1969, 25, 925-946.
(56) Ostoréro, J.; Leblanc, M. IUCr. Room-temperature structure of $\mathrm{La}_{2} \mathrm{O}_{2} \mathrm{~S}_{2}$. Acta Crystallogr., Sect. C: Cryst. Struct. Commun. 1990, 46, 1376-1378.

(57) Stephens, P. W. Phenomenological model of anisotropic peak broadening in powder diffraction. J. Appl. Crystallogr. 1999, 32, 281289.

(58) Ainsworth, C. M.; Lewis, J. W.; Wang, C.-H.; Coelho, A. A.; Johnston, H. E.; Brand, H. E. A.; Evans, J. S. O. 3D Transition Metal Ordering and Rietveld Stacking Fault Quantification in the New Oxychalcogenides $\mathrm{La}_{2} \mathrm{O}_{2} \mathrm{Cu}_{2-4 x} \mathrm{Cd}_{2 x} \mathrm{Se}_{2}$. Chem. Mater. 2016, 28, 3184-3195.

(59) Thomas, G. S.; Kamath, P. V.; Kannan, S. Variable temperature PXRD studies of $\mathrm{LiAl}_{2}(\mathrm{OH})_{6} \mathrm{X} . \mathrm{H}_{2} \mathrm{O}(\mathrm{X}=\mathrm{Cl}, \mathrm{Br})$ : Observation of disorder - order transformation in the interlayer. J. Phys. Chem. C 2007, 111, 18980-18984.

(60) Kogure, T.; Elzea-Kogel, J.; Johnston, C. T.; Bish, D. L. Stacking Disorder in a Sedimentary Kaolinite. Clays Clay Miner. 2010, $58,62-71$.

(61) Engelhardt, L. M.; Figgis, B. N. Magnetic susceptibility of cerium oxides. J. Chem. Soc. A 1969, 2933.

(62) Bradley, C. J.; Cracknell, A. P. Mathematical Theory of Symmetry in Solids; Clarendon Press: Oxford, 1972.

(63) Allen, J. P.; Scanlon, D. O.; Watson, G. W. Electronic structures of silver oxides. Phys. Rev. B: Condens. Matter Mater. Phys. 2011, 84, 115141.

(64) Blandy, J. N.; Boskovic, J. C.; Clarke, S. J. Synthesis and magnetic structure of the layered manganese oxide selenide $\mathrm{Sr}_{2} \mathrm{MnO}_{2} \mathrm{Ag}_{1.5} \mathrm{Se}_{2}$. J. Solid State Chem. 2017, 245, 61-66.

(65) Palazzi, M.; Carcaly, C.; Flahaut, J. Un nouveau conducteur ionique (LaO)AgS. J. Solid State Chem. 1980, 35, 150-155.

(66) Ishikawa, K.; Kinoshita, S.; Suzuki, Y.; Matsuura, S.; Nakanishi, T.; Aizawa, M.; Suzuki, Y. Preparation and Electrical Properties of $(\mathrm{LaO}) \mathrm{AgS}$ and $(\mathrm{LnO}) \mathrm{CuS}(\mathrm{Ln}=\mathrm{La}, \mathrm{Pr}$, or Nd). J. Electrochem. Soc. 1991, 138, 1166.

(67) Schleid, T.; Lauxmann, P.; Bartschb, C.; Doert, T. Rare Earth Metal Disulfides - Syntheses and Crystal Structures of $\alpha-\mathrm{CeS}_{2}, \alpha$ $\mathrm{NdS}_{2}, \beta-\mathrm{LaS}_{2}, \beta-\mathrm{CeS}_{2}$ and $\beta-\mathrm{PrS}_{2}$. Z. Naturforsch., B: J. Chem. Sci. 2009, 64b, 189-196.

(68) McTaggart, F. K.; Wadsley, A. D. The sulphides, selenides, and tellurides of titanium, zirconium, hafnium, and thorium i. preparation and characterization. Aust. J. Chem. 1958, 11, 445-457.

(69) Amoretti, G.; Calestani, G.; Giori, D. C. The Refined Structure of $\mathrm{ThS}_{2}$ and the Implications on the Superposition Model Analysis of $\mathrm{ThS}_{2} \mathrm{Gd}^{3+}$ Spin Hamiltonian Parameters. Z. Naturforsch., A: Phys. Sci. 1984, 39, 778-782. 